\title{
Activation of CNS Circuits Producing a Neurogenic Cystitis: Evidence for Centrally Induced Peripheral Inflammation
}

\author{
Luc Jasmin, ${ }^{1,2}$ Gabriella Janni, ${ }^{2}$ Herbert J. Manz, ${ }^{4}$ and Samuel D. Rabkin ${ }^{1,3}$ \\ Departments of ${ }^{1}$ Neurosurgery, ${ }^{2} \mathrm{Cell}$ Biology, ${ }^{3}$ Microbiology and Immunology, and ${ }^{4}$ Pathology, Georgetown University \\ Medical Center, Washington, DC 20007
}

\begin{abstract}
We present a model of neurogenic cystitis induced by viral infection of specific neuronal circuits of the rat CNS. Retrograde infection by pseudorabies virus (PRV) of neuronal populations neighboring those that innervate the bladder consistently led to a localized immune response in the CNS and bladder inflammation. Infection of bladder circuits themselves or of circuits distant from these rarely produced cystitis. Absence of virus in bladder and urine ruled out an infectious cystitis. Total denervation of the bladder, selective C-fiber deafferentation, or bladder sympathectomy prevented cystitis without affecting the CNS disease, indicating a neurogenic component to the inflammation. The integrity of central bladder-related circuits is necessary for the appearance of bladder inflammation, because
\end{abstract}

Models of neurogenically mediated cystitis are usually produced by exposing the bladder to chemical irritants (Cox, 1979; McMahon and Abel, 1987). Neurogenic components of this inflammation include the release of proinflammatory neurotransmitters by the peripheral branch of sensory and autonomic postganglionic neurons, together with activation of CNS bladder circuits (Lecci et al., 1994; Lantéri-Minet et al., 1995; Bon et al., 1996; Vizzard et al., 1996; Callsen-Cencic and Mense, 1997). It remains unknown whether these CNS circuits are conscripted as epipathogenic co-factors to an essentially peripheral phenomenon. Certainly, there is clinical evidence for a role of the CNS in rheumatoid arthritis, where hemispheric lesions prevent or reduce the disease contralaterally (Levine et al., 1985a,b). In rat models of peripheral inflammation, inhibition of NMDA receptors or stimulation of $\mathrm{A}_{1}$ adenosine receptors in the spinal cord blocks peripheral accumulation of neutrophils (Bong et al., 1996).

During a previous study (Jasmin et al., 1997b), we observed the appearance of a hemorrhagic cystitis after inoculation of pseudorabies virus (PRV) into the abductor caudae dorsalis (ACD) tail muscle of the rat. Bladder denervation prevented the cystitis, indicating a neurogenic dependence. The consistent infection of CNS neurons neighboring bladder circuitry suggested a relationship between the peripheral inflammation and the central viral disease, especially because viral infection of other neuronal populations not adjacent to bladder circuits (after inoculation at other sites) was not followed by cystitis.

\footnotetext{
Received Aug. 21, 1998; accepted Sept. 14, 1998.

This work was supported by the Medical Research Council (Canada). We are very grateful to Drs. Honghzi Guo and Lian Sheng Liu, Mr. Daniel Fitzsimmons, Ms. Jinwen Tang, and Ms. Anu Iyer for expert technical assistance.

Correspondence should be addressed to Dr. Luc Jasmin, Research Building, Room W221, Georgetown University Medical Center, 3970 Reservoir Road NW, Washington, DC 20007.

Copyright (C) 1998 Society for Neuroscience $\quad 0270-6474 / 98 / 1810016-14 \$ 05.00 / 0$
}

only CNS lesions affecting bladder circuits, i.e., bilateral dorsolateral or ventrolateral funiculectomy, as well as bilateral lesions of Barrington's nucleus/locus coeruleus area, prevented bladder inflammation. The close proximity in the CNS of noninfected visceral circuits to infected somatic neurons would thus permit a bystander effect, leading to activation of the sensory and autonomic circuits innervating the bladder and resulting in a neurogenic inflammation localized to the bladder. The present study indicates that CNS dysfunction can bring about a peripheral inflammation.

Key words: neuroimmune process; herpesviridae infection; nitric-oxide synthase; mad itch; urinary bladder; pain

The high neurotropism of PRV results in reproducible circuitspecific infection. PRV undergoes retrograde transneuronal transport to the CNS through neural circuits innervating the inoculated organ and is cleared from the inoculation site (Card et al., 1990; Strack and Loewy, 1990; Bouma et al., 1997; Jasmin et al., 1997a). Once in the CNS, PRV undergoes cycles of replication and transmission over a few days with minimal cytopathic effect, during which time rats present increasing neurological manifestations. Infected neurons rapidly shut off protein synthesis (Berthomme et al., 1993) while also inducing an immune response (Card et al., 1993; Rinaman et al., 1993; Card and Enquist, 1995). Despite this loss of function in infected neurons, other neurons are activated. In fact, animals vigorously scratch and groom dermatomes corresponding to the infected spinal segments, a feature so prevalent that the disease is termed "mad itch" (Gustavson, 1986). Accordingly, increased neuronal activity has been documented in PRV infection, likely resulting from changes in the extracellular milieu caused by ionic imbalance and/or the presence of immune cell mediators (Liao et al., 1991). We hypothesized that such increased activity in bladder circuits, i.e., neurons adjacent to infected cells, was responsible for the neural induction of the cystitis.

To test this hypothesis, we followed viral progression and immune response [using inducible nitric oxide synthase (iNOS) as a leukocyte marker] in the CNS in relation to the onset of cystitis. The neurogenic nature of the cystitis was confirmed by the preventative effect of limited bladder denervations. Spinal and brainstem lesions served to examine whether integrity of central urinary circuits was necessary for the appearance of cystitis. Importantly, to ensure that the bladder inflammation was not caused by a primary peripheral immune response to the virus, we also assessed the presence of PRV in the bladder parenchyma and urine. 


\section{MATERIALS AND METHODS}

One hundred and eighty-seven male Sprague Dawley rats (270-300 gm) (Harlan Sprague Dawley, Indianapolis, IN) were used in the study. All animals were exposed to light $12 \mathrm{hr}$ per day; food and water were available ad libitum. Animal procedures were approved by the Georgetown University Animal Care and Use Committee. During surgical procedures anesthesia was achieved with $1.0-1.5 \%$ halothane and $40 \%$ oxygen in room air.

\section{Cell culture and virus titration}

The Bartha strain of PRV, obtained from Dr. Lynn Enquist (Princeton University, Princeton, NJ), was used in all experiments. Pig kidney cells (PK-15, ATCC CCL33) were cultivated in DMEM with $10 \%$ fetal calf serum (Hyclone, Logan UT), L-glutamine $(0.3 \mathrm{mg} / \mathrm{ml})$, and antibiotics. The presence of infectious PRV was determined by plaque assay. Urine samples and biopsies of bladder and spine were obtained under sterile conditions. Urine samples were obtained after exposing the bladder through a laparotomy. With a 30 ga needle, the bladder was punctured, and $0.6 \mathrm{ml}$ of urine was removed. Biopsies of the bladder wall $(0.5 \times 0.5$ $\mathrm{cm}$ ) and L1-L2 and S1-S2 spinal cord were distributed to cryotubes containing $200 \mu \mathrm{l}$ of DMEM. Samples were quick-frozen and stored at $-80^{\circ} \mathrm{C}$ until use.

For virus titration, samples were frozen/thawed three times and sonicated for $1 \mathrm{~min}$ at $4^{\circ} \mathrm{C}$. The bladder sample was further minced with a scalpel. Viral samples were serially diluted in PBS with glucose $(1 \mathrm{mg} / \mathrm{ml})$ and $1 \%$ heat-inactivated fetal calf serum (Hyclone). Confluent monolayers of PK-15 cells, in six-well dishes, were inoculated with $0.7 \mathrm{ml}$ of diluted virus. After $1 \mathrm{hr}$ at $37^{\circ} \mathrm{C}$, the virus inoculum was removed, and the cells were overlaid with $1 \%$ methylcellulose in DMEM supplemented with $2 \%$ heat-inactivated fetal calf serum. When plaques were visible in control wells (PRV infected), after 3-4 d, the overlay was removed, and the cells were fixed with methanol and stained with Giemsa. Plaques were counted by an investigator blind to the treatment, and the virus titers were expressed as plaque-forming units (pfu). To control for virocidal activity present in the urine or tissue samples, PRV $(1 \mu \mathrm{l})$ was incubated at room temperature for 10 min with tissue samples $(9 \mu \mathrm{l})$ before serial dilution ( $\sim 100 \mathrm{pfu}$ plated/well) and then titered as described above.

\section{Nondenervated animals}

After inoculation, rats were monitored for signs of disease. All behavioral observation and analysis were performed by experimenters blind to the treatment. Nociceptive behaviors (see Results) were easily distinguishable from other signs of CNS viral disease [anorexia, weight loss, piloerection, altered sleep-wake cycle, head bobbing, diminished social interactions, and periods of unprovoked aggression toward cagemates ( 3 rats per cage)], which usually became noticeable at the end of the fourth day after PRV inoculation. Weight loss was the most reliable index of severity of CNS disease. It was quantified as follows: loss of $<4 \%(+)$, loss of $4-8 \%(++)$, and loss of $>8 \%(+++)$.

Striate muscle inoculation. Animals received a total of $4 \times 10^{6} \mathrm{pfu}$ of virus in $10 \mu \mathrm{l}$ into either the ACD, the gracilis of the hindlimb, or the extensor digitorum lateralis of the forelimb, using a $10 \mu \mathrm{l}$ Hamilton microsyringe. Care was taken to ensure that the viral inoculum did not contaminate cutaneous tissue. To control for nonspecific spread of the virus around the injection site, $10 \mu \mathrm{l}$ of the viral suspension was dropped onto the surface of the ACD without penetrating the muscle fascia $(n=$ $3)$. A second set of control rats $(n=6)$ served to assess the effects of surgery and injection of culture media free of PRV into the ACD muscle. None of the controls developed any signs of disease. At autopsy, their bladders were normal in appearance.

Bladder inoculation. A $1.5 \mathrm{~cm}$ midline incision was made in the lower abdominal wall to expose the bladder. Each rat received three separate injections of PRV (totaling $4 \times 10^{6} \mathrm{pfu}$ ) distributed in the ventral and dorsal surfaces of the bladder, halfway between the dome and neck. The localization of each injection was confirmed by the visualization of a blister-like structure at the injection site.

\section{Denervated animals}

Primary afferent denervation. Resiniferatoxin was used to remove capsaicin-sensitive $\mathrm{C}$-fiber bladder primary sensory afferents, without affecting sympathetic innervation (Cervero and McRitchie, 1982) or the majority of myelinated primary afferents (Jancsó and Lawson, 1990; Yoshimura et al., 1998). This treatment was performed $24 \mathrm{hr}$ after ACD inoculation to ensure that viral uptake and transport from the injection site had occurred. Preliminary experiments demonstrated that the medium necessary to solubilize capsaicin, $10 \%$ Tween 80 and $10 \%$ ethanol (Maggi et al., 1989), reduced PRV-induced bladder inflammation when given alone. Equipotent doses of resiniferatoxin require only $1 \%$ Tween 80 and $0.5 \%$ ethanol to be solubilized, and at these concentrations Tween 80 and ethanol do not affect the inflammation. In this vehicle, resiniferatoxin solution was directly instilled into the bladder lumen (Craft et al., 1995). Voiding efficiency remained unchanged after this treatment (Petsche et al., 1983; Baranowski et al., 1986; Such and Jancsó, 1986; Maggi et al., 1989).

A $1.5 \mathrm{~cm}$ midline incision in the lower abdominal wall served to expose the bladder. Ten nanomoles of resiniferatoxin in $1.0 \mathrm{ml}$ of vehicle $(1 \%$ Tween $80 / 0.5 \%$ ethanol) were instilled transmurally into the bladder lumen using a 30 ga needle and then removed after $20 \mathrm{~min}$. The bladder was then washed with PBS, $\mathrm{pH} 7.4$, and the wound was closed with interrupted silk sutures. Controls were injected with the vehicle only. The blink reflex in response to corneal stimulation was assessed in all animals $24 \mathrm{hr}$ later to exclude possible systemic effects of resiniferatoxin (Craft et al., 1995).

Sympathectomy. Preganglionic sympathectomy was achieved by sectioning the intermesenteric nerve, and postganglionic sympathectomy was achieved by sectioning both hypogastric nerves. A lower midline abdominal incision was made, and the intestine and bladder were retracted to expose the inferior mesenteric ganglion and its afferents, mainly the intermesenteric nerve, and its efferent branches, the hypogastric nerves [Baron et al. (1988), their Fig. 1]. Sham surgery consisted of sectioning only one hypogastric nerve. PRV was inoculated in the right $\mathrm{ACD}$ during the same procedure. None of the rats were found to have urinary retention during the period after the operation.

Pelvic ganglionectomies. The periprostatic space was dissected to expose the pelvic plexus, where the major pelvic ganglion lies as a discrete structure within the transparent fascia over the lateral lobes of the prostate. Unilateral or bilateral pelvic ganglionectomies were made, thereby partially or completely denervating visceral innervation to the bladder (Martinez-Piñeiro et al., 1993). After the operation, the bladder was emptied twice daily by performing an abdominal Créde maneuver.

Spinal lesions. These included the following: complete sections at T8, bilateral dorsolateral funiculus (DLF) or ventrolateral funiculus (VLF) lesions at T7 or T8, and dorsal funiculi (DF) lesions at T13-L1. Using microsurgical techniques, the spinal cord was exposed after a laminectomy, and the dura was opened and reflected laterally. To section the spinal cord a no. 11 blade was used, after which Gelfoam was inserted in the gap to control possible bleeding. Selective DLF, VLF, or DF lesions were made by pinching the funiculus with ultrafine no. 5 jeweler's forceps under high magnification using a surgical microscope. This compressive technique minimizes local hemorrhage while permitting complete interruption of the targeted tract. An observer blind to the intent of the surgery mapped the extent of the lesions on Nissl-stained serial transverse sections of the spinal segment. For rats with complete spinal section, the bladder was emptied twice daily by performing an abdominal Créde maneuver.

Brainstem lesions. Unilateral or bilateral excitotoxic lesions of the Barrington's nucleus/locus coeruleus area (Bar/LC) or of the adjacent reticular formation were made by microinjection of $500 \mathrm{nl}$ of a $0.5 \%$ aqueous solution of ibotenic acid (Sigma, St. Louis, MO) with a glass pipette with a $50 \mu \mathrm{m}$ tip outer diameter. Stereotaxic coordinates were obtained from the atlas of Paxinos and Watson (1997). Ibotenic acid creates discrete cellular lesions and spares fibers of passage (Iadecola et al., 1987; Meunier and Destrade, 1988; Jasmin et al., 1997a). According to the time of viral inoculation, the lesions were made at three different time points: (1) both lesions (bilaterally) were made 2 weeks before inoculation $(n=6),(2)$ a delay of 1 week between the left and right lesion was allowed $(n=8)$ and PRV was injected in the ACD immediately after the last lesion, or (3) PRV was inoculated $24 \mathrm{hr}$ before the second lesion was made $(n=6)$. The location and extent of each lesion was determined on $60 \mu \mathrm{m}$ Nissl-stained serial transverse sections. The lesions were easily identifiable by the marked gliosis and degenerated neuronal profiles, the extent of which served to demarcate the outer borders around a central core of pyknotic cells.

\section{Tissue processing}

At the end of the experiments and before perfusion, rats were anesthetized with a mixture of ketamine and xylazine $(100 \mathrm{mg}$ and $15 \mathrm{mg} / \mathrm{kg})$. All animals, except the ones from which viral cultures were done (see next paragraph), were then administered $50 \mathrm{mg} / \mathrm{kg}$ Evans blue (Sigma, 
St. Louis, MO) in a tail vein to assay plasma protein extravasation in the bladder and other tissues (Carr and Wilhelm, 1964). Fifteen minutes later a punch biopsy of the bladder wall $(0.8 \mathrm{~cm}$ in diameter $)$ was obtained, transferred to a glass tube, and dried at $70^{\circ} \mathrm{C}$ for $24 \mathrm{hr}$ before its Evans blue content was measured (see below). Evans blue measurement of rectal, prostate, and lumbosacral spinal cord was also made in four PRV-ACDinjected and four sham (culture medium only)-injected rats.

In a subgroup of rats $(n=16)$, before the bladder biopsy, samples (urine, bladder, and spinal cord) were obtained for viral culture using sterile technique (described above). Biopsies and urine samples were obtained multiple times before perfusion at 48, 60, 67, 84, 91, 96, 108, and $112 \mathrm{hr}$ after inoculation in the ACD muscle $(n=2$ per time after inoculation). Samples were also collected from sympathectomized rats $(n=3)$ at $144 \mathrm{hr}$ after inoculation, when they presented obvious signs of CNS viral disease (i.e., ++ to +++ ).

Rats were then perfused through the ascending aorta with Tyrode's solution followed by an aldehyde fixative. The brain and spinal cord, bladder, prostate, and rectum were removed and transferred into the same fixative solution overnight, and then transferred into a $25 \%$ buffered sucrose solution to achieve cryoprotection.

Immunostaining. Serial sections (60 $\mu \mathrm{m}$ thick) were obtained using a freezing microtome or cryostat. To identify the distribution of virally infected cells, $60-\mu \mathrm{m}$-thick sections of brain, spinal cord, and bladder were immunostained with an anti-PRV rabbit polyclonal antiserum directed against acetone-inactivated PRV [serum Rb-134, 1:20,000 (a generous gift from Dr. Lynn Enquist)]. Immunostaining for iNOS and ED1 were performed to examine the anatomical distribution of inflammatory cells in the spinal cord and brain. A rabbit polyclonal iNOS antiserum (Upstate Biotechnology, Lake Placid, NY), raised against purified RAW 264.7 cells activated by $\gamma$-interferon and bacterial lipopolysaccharide, was used at a dilution of $1: 10,000$. Selected sections were also stained with the monoclonal ED1 antiserum (Serotec, Kidlington Oxford, UK) at a dilution of 1:500. This serum recognizes a cytoplasmic epitope common to monocytes and macrophages and does not label activated microglia (Milligan et al., 1991a,b; Rinaman et al., 1993). To identify the neurons of the locus coeruleus, we used a rabbit anti-tyrosine hydroxylase (TH) antiserum (Eugene Tech) at a dilution of 1:20,000. TH staining also served to confirm the location of Barrington's nucleus, which is medial and ventral to the rostral third of the locus coeruleus. All immunocytochemical procedures were performed as described previously (Jasmin et al., 1997a,b). The specificity of labeling was verified by omission of the primary antibody on representative sections from each experiment.

\section{Tissue analysis}

Tissue analysis was performed by investigators blind to the treatment. The distribution of immunolabeled sections and hematoxylin and eosin (H\&E)-stained sections was studied with bright-field microscopy using low and high magnification. Identification of brainstem nuclei was performed on Nissl-stained sections using the atlas of Paxinos and Watson (1997). A Nikon Optiphot-2 microscope (Nikon, Tokyo, Japan) captured images through an analog VE-1000 camera (Dage-MTI, Michigan, IN) connected to a VC70 Control Unit (Dage-MTI). The image was relayed to an 8100/100AV Power Macintosh computer (Apple Computers, $\mathrm{Cu}$ pertino, CA) through a high-resolution video capture board (PDI, Redmond, WA). Adobe Photoshop (Adobe Software, Mountain View, CA) was used to adjust contrast and brightness of images and to affix labels.

Measure of protein extravasation using the Evans blue dye colorimetric method. Dried bladder, prostate, rectum, and spinal cord biopsies were weighed and then immersed in $1 \mathrm{ml}$ of formamide (Fisher, Pittsburgh, PA) for $72 \mathrm{hr}$ in total darkness. The formamide/Evans blue solution was then gently aspirated without disturbing the tissue at the bottom of the glass tube and transferred to a $1 \mathrm{ml}$ glass cell (Fisher). The refractive index was measured three times using a Lambda Bio spectrophotometer (Perkin-Elmer, Norwalk, CT) set at $620 \mathrm{~nm}$ wavelength (Carr and Wilhelm, 1964) with pure formamide as the reference. The three measures were then averaged, and the mean was converted to micrograms of Evans blue by reporting the results on a standard curve of the refractive index versus dilution of Evans blue.

\section{Statistical analyses}

Values are expressed as the mean \pm SE. Data were analyzed using a one-way ANOVA, followed by post hoc comparison (Scheffé's $F$ procedure) to confirm significant differences between groups. Before the analysis, a $p$ value $<0.05$ was chosen as indicating significance.

\section{RESULTS}

\section{Nondenervated animals}

\section{Nociceptive behavior}

Approximately $96 \mathrm{hr}$ after ACD inoculation, rats began to repeatedly groom their lower abdomen on the midline, scratch their flanks with their hindpaws, and adopt a rounded-back posture (cystitis score + ). The frequency of grooming and scratching increased thereafter. Beginning at approximately $110 \mathrm{hr}$, short episodes (2-3 sec) of backward walking or hopping were also noted $($ score ++$)$. Some rats walked with their hindlimbs extended, an antalgic reflex to avoid pressure to the lower abdomen. Rats also had periods of immobility lasting up to $10 \mathrm{~min}$, interrupted by bouts of vigorous grooming of the lower abdomen and scratching of the flanks. When this grooming became selfinjurious (score +++ ), rats were euthanized. In contrast, grooming behaviors in rats inoculated in the bladder were mostly oriented toward the base of the tail, and to a lesser degree to the hindpaws rather than to the abdomen, and they did not adopt any abnormal posture or gait. The base of the tail was erythematous and swollen. Hindlimb-inoculated rats would all show intense grooming of hindpaws and flanks. Half of them also directed this behavior to the base of their abdomen and had an inflamed bladder, as seen in ACD-inoculated rats. Animals inoculated in a forelimb muscle would repeatedly scratch their flanks and overgroom their forepaws.

\section{Macroscopy}

The severity of bladder inflammation was determined by macroscopic examination of the bladder by investigators blind to the treatment. ACD-inoculated rats presenting nociceptive behavior toward the lower abdomen all had macroscopical signs of bladder inflammation. Post hoc analysis additionally revealed that the degree of changes in the bladder wall paralleled the severity of behavioral signs of cystitis (Table 1): Stage 0: translucent bladder wall (Fig. 1A); Stage 1: isolated areas of petechial hemorrhage in the bladder wall located on both bladder dome and base. These changes were better seen after administration of Evans blue dye (Fig. $1 B$ ): Stage 2: confluence of the petechial hemorrhage and discrete macroscopic hematuria (pink urine). Repeated grooming of the lower abdomen as well as abnormal posture were a constant feature in these rats: Stage 3: diffuse hemorrhagic thickening of the bladder wall and macroscopic hematuria; the bladder wall was opaque because of the abundant hemorrhagic infiltrate (Fig. 1C). Rats at this stage showed the most prevalent nociceptive behavior indicative of cystitis. In addition, they often had a moderately distended bladder (up to 2-3 ml of urine, compared with $1 \mathrm{ml}$ in normal rats). Of note, systematic examination in all rats of the pelvic and abdominal cavities did not reveal evidence of inflammation in any other viscera, including the kidneys, rectum, colon, small intestine, prostate, seminal vesicles, liver, spleen, stomach, and testicles. The colon, however, was often distended, a phenomenon that was attributed to the loss of its preganglionic innervation attributable to viral invasion of spinal neurons. Two rats injected in the bladder presented behavioral signs of cystitis and showed stage 2 and 3 macroscopical changes at autopsy. The other bladderinoculated rats had normal bladders at autopsy (Table 1).

\section{Measure of plasma protein extravasation}

Post hoc analysis demonstrated that intravenous injection of Evans blue caused the bladder to turn densely blue in all animals with behavioral or macroscopical signs of inflammation (Fig. 2). 


\begin{tabular}{|c|c|c|c|c|c|c|}
\hline Treatment preceding inoculation & Inoculation site $^{a}$ & $\begin{array}{l}\text { Delay before } \\
\text { perfusion }\end{array}$ & $n$ & $\begin{array}{l}\text { Signs of viral } \\
\text { disease }^{b}\end{array}$ & $\begin{array}{l}\text { Behavioral signs } \\
\text { of cystitis }^{c}\end{array}$ & $\begin{array}{l}\text { Macroscopical } \\
\text { grade of cystitis }^{d}\end{array}$ \\
\hline None & $\mathrm{ACD}$ & $\leq 80 \mathrm{hrs}$ & 28 & None & None & 0 \\
\hline None & $\mathrm{ACD}$ & 81-95 hrs & 10 & + & + & $0-1$ \\
\hline None & $\mathrm{ACD}$ & $\geq 96 \mathrm{hrs}$ & 36 & $++/+++$ & $++/+++$ & $2-3$ \\
\hline None & Surface of ACD & $\geq 96 \mathrm{hrs}$ & 3 & None & None & 0 \\
\hline None & Bladder & $<96$ hrs & 7 & None/+ & None & 0 \\
\hline None & Bladder & $\geq 96$ hrs & 12 & $++/+++$ & In two rats $s^{e}++$ & In two rats ${ }^{e} 1-2$ \\
\hline None & Forelimb & $\geq 96 \mathrm{hrs}$ & 4 & $++/+++$ & In one rat + & 1 \\
\hline None & $\begin{array}{l}\text { Hindlimb } \\
\text { ACD (culture }\end{array}$ & $\geq 96 \mathrm{hrs}$ & 4 & $++/+++$ & In two rats ++ & $2-3$ \\
\hline None & $\begin{array}{l}\text { medium only }^{f} \text { ) } \\
\text { Bladder (culture }\end{array}$ & $\geq 96 \mathrm{hrs}$ & 6 & None & None & 0 \\
\hline None & medium only) & $\geq 96 \mathrm{hrs}$ & 4 & None & None & 0 \\
\hline Intravesical resiniferatoxin & $\mathrm{ACD}$ & $\geq 96 \mathrm{hrs}$ & 7 & $++/+++$ & None & 0 \\
\hline Vehicle & $\mathrm{ACD}$ & $\geq 96 \mathrm{hrs}$ & 3 & $++/+++$ & $++/+++$ & $2-3$ \\
\hline Intemesenteric nerve section & $\mathrm{ACD}$ & $\geq 96 \mathrm{hrs}$ & 4 & $++/+++$ & None & 0 \\
\hline Hypogastric nerves section & $\mathrm{ACD}$ & $\geq 96 \mathrm{hrs}$ & 4 & $++/+++$ & In two rats + & 1 \\
\hline Unilateral hypogastric nerve section & $\mathrm{ACD}$ & $\geq 96 \mathrm{hrs}$ & 2 & $++/+++$ & $++/+++$ & $2-3$ \\
\hline \multicolumn{7}{|l|}{ Pelvic ganglionectomy } \\
\hline Bilateral & $\mathrm{ACD}$ & $\geq 96 \mathrm{hrs}$ & 5 & $++/+++$ & None & 0 \\
\hline Unilateral & $\mathrm{ACD}$ & $\geq 96 \mathrm{hrs}$ & 6 & $++/+++$ & $++/+++$ & $2-3$ \\
\hline Sham surgery & $\mathrm{ACD}$ & $\geq 96 \mathrm{hrs}$ & 2 & $++/+++$ & $++/+++$ & $2-3$ \\
\hline \multicolumn{7}{|l|}{ Spinal lesions } \\
\hline Complete transection (T8) & $\mathrm{ACD}$ & $\geq 96 \mathrm{hrs}$ & 3 & $++/+++$ & None & 0 \\
\hline DLF funilectomy & $\mathrm{ACD}$ & $\geq 96 \mathrm{hrs}$ & 5 & $++/+++$ & None & 0 \\
\hline VLF funilectomy & $\mathrm{ACD}$ & $\geq 96 \mathrm{hrs}$ & 3 & $++/+++$ & None & 0 \\
\hline DF funilectomy & $\mathrm{ACD}$ & $\geq 96 \mathrm{hrs}$ & 3 & $++/+++$ & $++/+++$ & $2-3$ \\
\hline Sham surgery & ACD & $\geq 96 \mathrm{hrs}$ & 6 & $++/+++$ & $++/+++$ & $2-3$ \\
\hline Bar/LC bilateral lesions & $\mathrm{ACD}$ & $\geq 96 \mathrm{hrs}$ & 10 & $++/+++$ & None & 0 \\
\hline $\mathrm{Bar} / \mathrm{LC}$ unilateral lesions & $\mathrm{ACD}$ & $\geq 96 \mathrm{hrs}$ & 3 & $++/+++$ & $+/++$ & 2 \\
\hline Reticular formation bilateral lesions & $\mathrm{ACD}$ & $\geq 96 \mathrm{hrs}$ & 10 & $++/+++$ & $+/++$ & 2 \\
\hline
\end{tabular}

${ }^{a}$ All rats were inoculated with PRV unless specified.

${ }^{b}$ See Material and Methods.

${ }^{c}$ See Results.

${ }^{d}$ See Results.

${ }^{e}$ Apart from these two rats, all bladder-inoculated animals showed no behavioral, macroscopical, or microscopical signs of cystitis.

${ }^{f}$ These rats served as controls for the bladder's histology and Evans blue dye measurements on bladder tissue.

Furthermore, in ACD-inoculated rats, a significant increase in Evans blue content in the bladder tissue was measured as early as $81 \mathrm{hr}$ after inoculation, when behavioral signs of cystitis were still absent, thus making Evans blue dye extravasation an early marker of inflammation. It was not a useful measure of the degree of cystitis, however, because the Evans blue dye content in the bladder was the same for all rats showing signs of cystitis independent of the severity $(p>0.05)$. Finally, the Evans blue dye content in the rectum, prostate, and lumbosacral spinal cord in a subset of animals with advanced cystitis $(n=4)$ and that of the bladder of rats inoculated in the bladder wall were not significantly different from normal controls $(p>0.05)$.

\section{Microscopy}

H\&E-stained sections of the bladders (post hoc analysis) also revealed evidence of inflammation in all animals exhibiting macroscopical anomalies or significant plasma extravasation. At approximately $80 \mathrm{hr}$ after inoculation, however, these changes were discrete, consisting of swelling of the lamina propria. Later, the changes consisted of accumulation of an inflammatory exudate in the extravascular space of the lamina propria and the muscular layer (detrusor), the cellular component of which consisted of leukocytes $(\approx 60 \%$ mononuclear and $40 \%$ polymorphonuclear) and red blood cells (Fig. 3A). The hemorrhagic component (red blood cells) increased as the cystitis advanced, with progressive disruption of the histoarchitecture of the epithelial and muscular layers. Erosions of the epithelial layer were seen with greater frequency at advanced stages. In contrast to other layers, the serosal layer remained intact. The rectal submucosa and prostatic interstitium under histological examination remained normal, even in rats with stage 3 bladder inflammation (Fig. 3C,D). In isolated cases that were observed beyond $120 \mathrm{hr}$ after inoculation, a discrete inflammatory infiltrate was noted in the submucosa of the colon and the interstitium of the prostate.

\section{Immunocytochemistry and viral cultures of the bladder}

PRV immunostaining of the bladder wall $(n=18)$ was consistently negative, independent of post-inoculation delay (24-136 

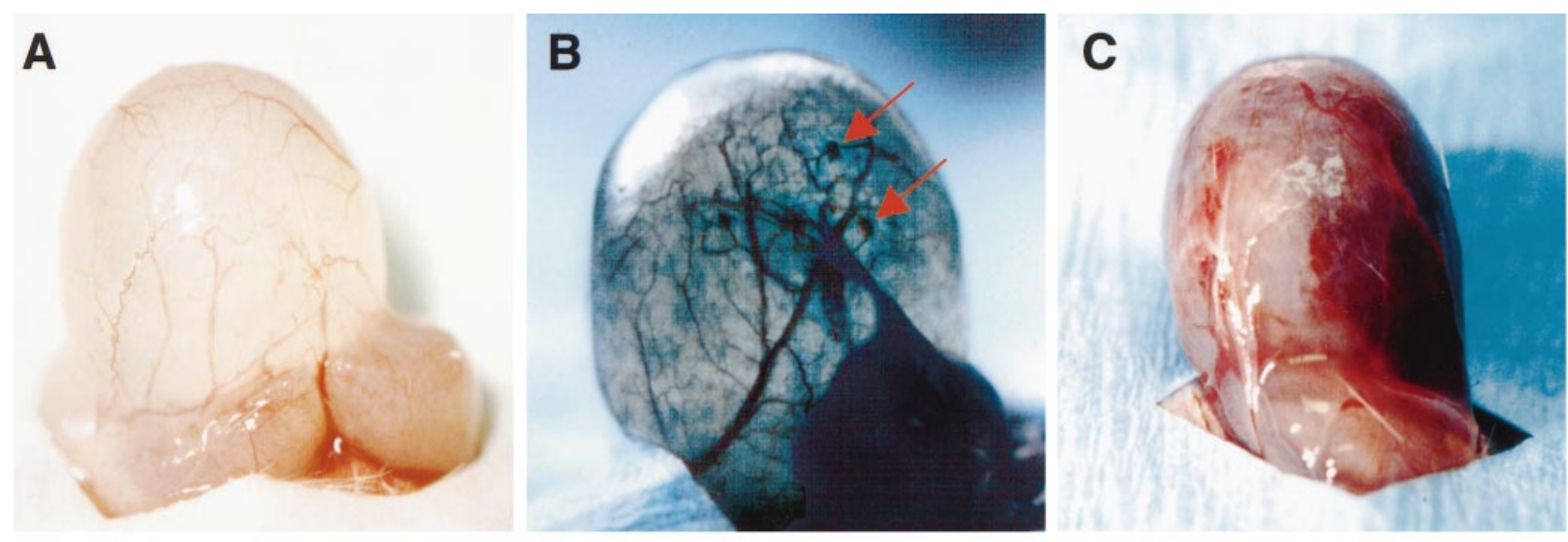

D

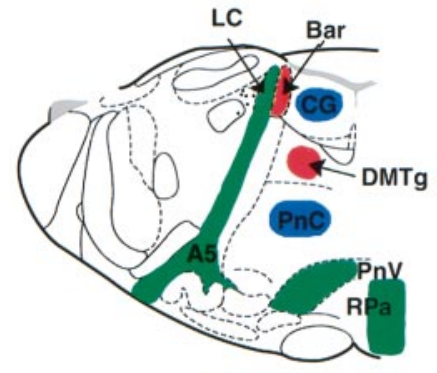

CAUDAL PONS
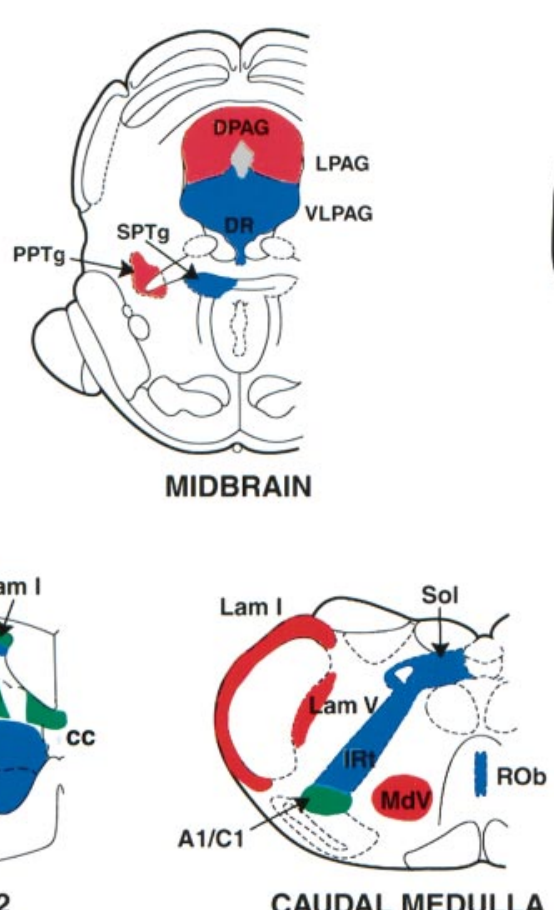

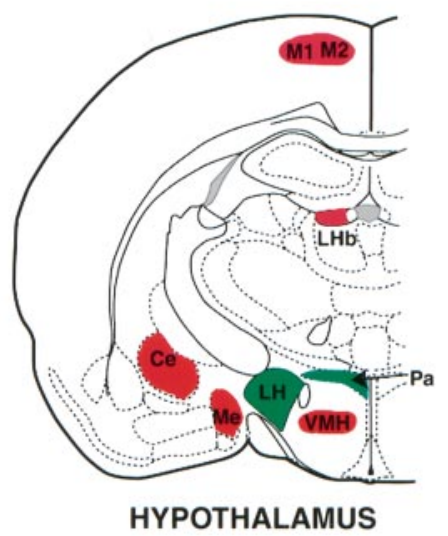

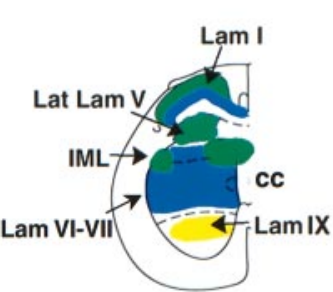

s1-s2

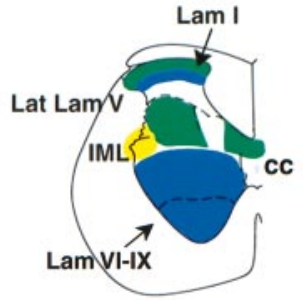

L1-L2
CAUDAL MEDULLA

Advanced

(96-112 hrs)

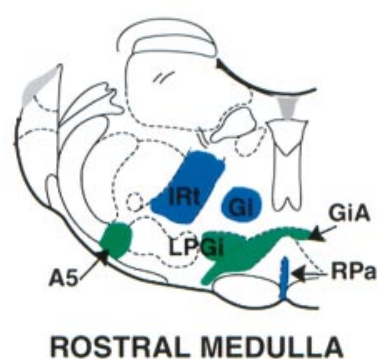

ROSTRAL MEDULLA

\section{Early Infection (48-71 hrs)}

Intermediate

(72-96 hrs)
Very Advanced (>120 hrs)

Figure 1. A-C, Photomicrographs of bladders taken immediately before perfusion. $A$, Macroscopic stage 0 at $136 \mathrm{hr}$ after intermesenteric nerve section and virus inoculation in the ACD. This picture was taken before Evans blue injection. The bladder appears entirely normal, and the animal was free of any signs suggestive of cystitis but presented signs of advanced viral disease $(+++)$. B, Macroscopic stage 1 at $135 \mathrm{hr}$ after selective section of both hypogastric nerves and virus inoculation in the ACD. This picture was taken after intravenous injection of Evans blue and demonstrated the early stage of bladder inflammation (stage 1), characterized by isolated areas of petechial hemorrhage (red arrows). There was also moderate urinary retention (2.5 $\mathrm{ml}$ of urine). Evans blue content was significantly increased compared with controls. This rat had no behavior suggestive of cystitis but did have signs of advanced viral disease $(+++)$. C, Macroscopic stage 3 at $118 \mathrm{hr}$ after unilateral hypogastric nerve section. The picture was taken before Evans blue injection. This rat had signs of both advanced $(+++)$ cystitis and advanced viral disease. $D$, Diagrams of transverse sections of the spinal cord at the level of parasympathetic (S1-S2) and sympathetic (L1-L2) preganglionic neurons innervating the bladder, as well as through the brainstem and brain, after ACD inoculation. Summary of the progression of virus infection for each region has been color-coded. A1/C1 adrenergic area (A1/C1), A5 adrenergic area (A5), Barrington's nucleus (Bar), central gray $(C G)$, central nucleus of amygdala $(C e)$, dorsal periaqueductal gray $(D P A G)$, dorsal raphe nucleus $(D R)$, dorsomedial tegmental area $(D M T g)$, gigantocellular reticular nucleus $(G i)$, gigantocellular reticular nucleus $\alpha(G i A)$, intermediate reticular nucleus (IRt), intermediolateral cell column (IML), laminae of the spinal cord and trigeminal nucleus caudalis (Lam I, Lam V, Lam VI-VII, Lam VI-IX, Lam IX), lateral half of spinal lamina V (Lat Lam V), lateral habenular nucleus $(L H b)$, lateral hypothalamus $(L H)$, lateral paragigantocellular nucleus $(L P G i)$, lateral periaqueductal gray $(L P A G)$, locus coeruleus $(L C)$, medial nucleus of amygdala $(M e)$, medullary reticular nucleus ventral $(M d V)$, nucleus of the solitary tract $(\mathrm{Sol})$, paraventricular hypothalamic nucleus $(\mathrm{Pa})$, pedunculopontine tegmental nucleus $(P P T g)$, pontine reticular nucleus caudal $(P n C)$, pontine reticular nucleus ventral $(P n V)$, primary and secondary motor cortex $(M 1$ and $M 2)$, raphe obscurus nucleus $(R O b)$, raphe pallidus nucleus $(R P a)$, subpeduncular tegmental nucleus $(S P T g)$, ventrolateral periaqueductal gray $(V L P A G)$, and ventromedial hypothalamic nucleus $(V M H)$. Diagrams and nomenclature adapted from the atlas of Paxinos and Watson (1997). 


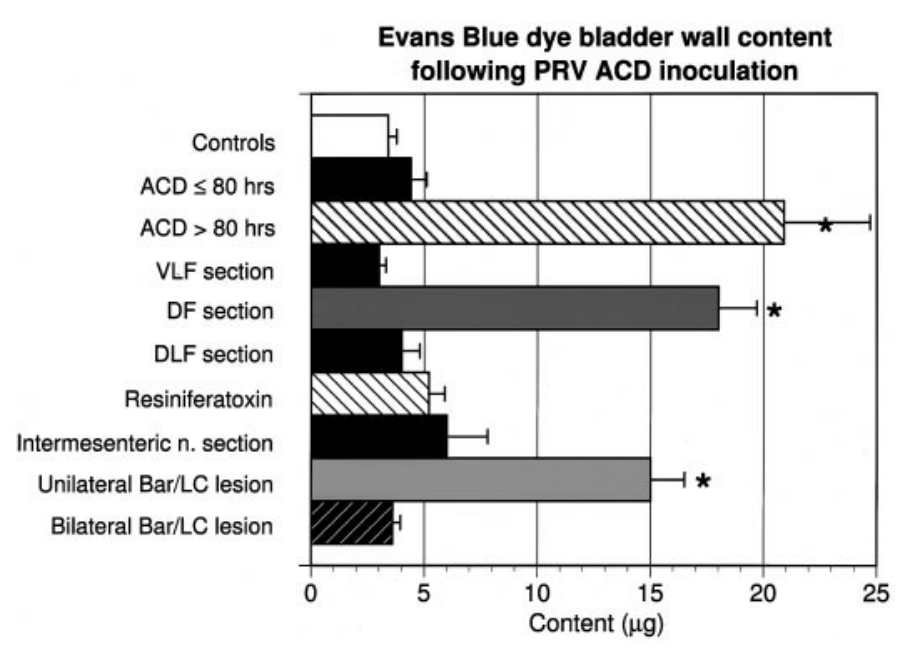

Figure 2. Histogram of Evans blue tissue content measured in bladders of nondenervated and denervated rats inoculated with PRV in the ACD. Normal controls were injected with culture medium only. Nondenervated rats were divided into two groups $(\leq 80 \mathrm{hr}$ and $>80 \mathrm{hr}$ ) based on preliminary results showing that the earliest time at which a significant increase in Evans blue could be detected was $81 \mathrm{hr}$. At this early time, however, none of the animals showed any signs of cystitis, which began to appear at $96 \mathrm{hr}$. Denervated rats were all perfused when they had unequivocal signs of CNS viral disease $(++$ or +++$)$, i.e., perfused $96 \mathrm{hr}$ or more post-inoculation. Error bars denote the SE of the mean. * denotes significant difference from controls $(p<0.05)$. The number of animals is listed in Table 1. $A C D$, Abductor caudalis dorsalis; Bar/LC, Barrington/locus coeruleus; $D F$, dorsal funiculus; $D L F$, dorsolateral funiculi; $V L F$, ventrolateral funiculi.

hr) or macroscopic stage of inflammation. Urine and bladder cultures were also negative for infectious virus (Fig. $4 A$ ), whereas addition of PRV to the urine or minced bladder samples before plaqueing on the PK-15 cells always resulted in plaque formation (Fig. $4 B$ ). Because the addition of urine or bladder tissue to the virus samples did not significantly alter $(p>0.05)$ the number of plaques compared with the input PRV titer, we concluded that there was no inhibitory or virocidal factor in the specimens that could have neutralized virus and masked its presence in the isolated tissue. In contrast to bladder and urine, spinal cord cultures from ACD-injected animals contained infectious virus. Lumbosacral spinal cord from two animals (115 hr after PRV infection, with cystitis) contained $5 \times 10^{5}$ and $1 \times 10^{7} \mathrm{pfu}$, respectively (Fig. $4 C$ ). Isolation of infectious virus from the spinal cord correlated with the extensive presence of PRVimmunoreactive cells in the spinal cord (see below) (Fig. 5).

\section{Viral spread in the CNS}

The pattern of PRV spread after ACD (Fig. 1D) or bladder inoculation was very consistent between the two inoculation sites. The following description of the spatial and temporal progression of this spread will not include the cervical and thoracic spinal segments, because of both the paucity of PRV neurons observed there and the lack of evidence for a significant role of these spinal areas in bladder function.

Lumbosacral spinal cord. After ACD inoculation, PRVimmunolabeled neurons were first visible at $48 \mathrm{hr}$ in the sympathetic intermediolateral cell column (IML) at T13-L2 bilaterally (Fig. 1D), and in the ipsilateral ventral horn from spinal segments S2-S3, where motoneurons innervating this muscle are found (Grossman et al., 1982). Twenty four hours later, labeled neurons were additionally seen in the sacral IML, the dorsal gray com- missure, and the intercalated areas at L6-S3 levels, where parasympathetic preganglionic neurons innervating the bladder are located (Nadelhaft and Booth, 1984; Nadelhaft and Vera, 1995). These neurons having no known direct connections with the $\mathrm{ACD}$, it is presumed that they became infected through connections with the motoneurons innervating this muscle. Also at $72 \mathrm{hr}$, immunopositive neurons appeared in the lumbar gray matter dorsal to the central canal (Fig. 5, cc, left panel, $72 \mathrm{hrs}$ ). At $84 \mathrm{hr}$, labeled neurons appeared in the lumbar and sacral dorsal horn. These were concentrated in lamina I and in the reticulated area of the gray matter (lateral lamina $\mathrm{V}$ ) where nociceptive neurons are located (Fig. 5, left panel, $84 \mathrm{hrs}$ ). Long dendrites extending from the IML to the reticulated area were often seen, suggesting a possible route through which dorsal horn neurons retrogradely became infected, because PRV would not enter the spinal cord through primary afferents (Jasmin et al., 1997b). At longer postinoculation times, labeled cells were additionally seen in laminae II, VI, VII, and VIII (Fig. 5, left panel, 96 hrs). Bladder inoculation resulted in a similar distribution of labeled neurons, with the difference that the parasympathetic IML (S1-S3) was labeled before the sympathetic IML (T13-L2). Also, motoneurons of the sacral cord remained unlabeled, as would be expected given the absence of somatic motor innervation to the bladder dome, where viral inoculations were made. Compared with ACD, limb inoculation resulted in much less PRV immunoreactivity in bladderrelated areas of the spinal cord, especially after forelimb inoculation, whereas labeling was dense in other spinal areas unrelated to bladder function. PRV-immunolabeled neurons were concentrated in the dorsal horn (ipsilateral $>$ contralateral) especially in the superficial dorsal horn (lamina I and outer II) and neck (mainly lateral lamina V); labeled cells were also noticeable around the central canal, especially dorsally. This labeling was concentrated in the lumbar cord after hindlimb inoculation and in the cervical cord after forelimb inoculation.

Brainstem. Labeling was always bilateral. After ACD inoculation, PRV neurons first appeared at $72 \mathrm{hr}$ in the A5 area and lateral paragigantocellularis and gigantocellularis $\alpha$ cell groups, followed 12 hr later by labeling of the $\mathrm{A} 1 / \mathrm{C} 1$ area, locus coeruleus, subcoeruleus, and raphe pallidus (Figs. 1D, $6 A$ ). A few labeled neurons were also seen in the parabrachial pigmented nucleus at the caudal end of the red nucleus, and in the hypothalamic paraventricular nucleus and lateral area. From 96 to 111 hr, PRV-positive cells were additionally visible in the nucleus of the solitary tract and adjacent intermedial reticular nucleus, nucleus raphe obscurus, nucleus gigantocellularis, especially in its ventral part, caudal pontine reticular nucleus, Kölliker-Fuse nucleus, central pontine gray matter, subpeduncular tegmental nucleus, ventrolateral region of the periaqueductal gray matter (PAG) and adjacent dorsal raphe nucleus, and last, the ventral tegmental area. Starting at $112 \mathrm{hr}$, PRV-positive cells appeared in Barrington's and pedunculopontine nucleus, and in the hypothalamic medial preoptic, retrochiasmatic, posterior, and ventromedial areas. At the latest stage only ( $>120 \mathrm{hr}$ ), additional labeling was present in lamina I and $\mathrm{V}$ of the trigeminal nucleus caudalis (caudal medulla in Figs. 1D), ventral medullary reticular nucleus, dorsomedial tegmental area, lateral and dorsal PAG (LPAG and DPAG), lateral habenular nucleus, central and medial nuclei of the amygdala, and primary and secondary motor cortices. The most apparent difference in labeling between ACD and bladderinoculated rats was the early labeling ( $72 \mathrm{hr}$ ) of Barrington's nucleus in the latter group (Fig. 6, compare $A, B$ at $96 \mathrm{hr}$ ). After bladder inoculation, PRV-immunolabeling of Barrington's nucleus (Fig. 6B) and other brainstem areas was comparable to what has been re- 

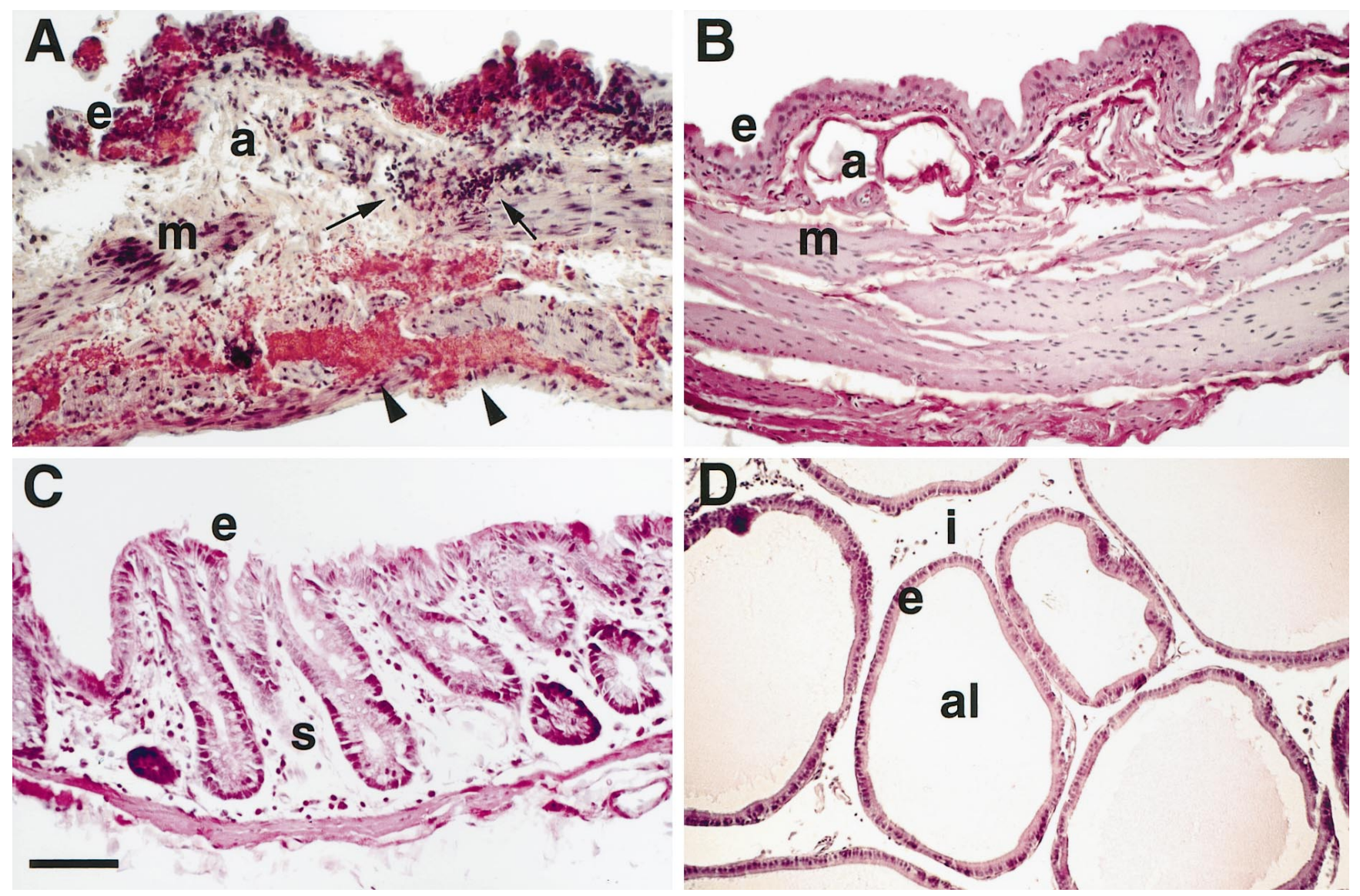

Figure 3. H\&E-stained sections. $A$, Bladder from an animal with macroscopic stage 3 cystitis. The epithelial $(e)$, adventitial $(a)$, and muscular $(m)$ layers are diff usely infiltrated by leukocytes (dark circular profiles, arrows) and red blood cells (arrowheads). B, The bladder from an animal with intermesenteric nerve section, in contrast, is normal on histological examination despite the advanced CNS viral disease. $C$, Large intestine and $(D)$ prostate from the same rat as in $A$. Both organs are devoid of inflammatory infiltrate. al, Prostatic alveolar cavity; $e$, bladder, intestinal, and prostatic epithelium; $i$, prostatic interstitium; $s$, intestinal submucosa. Scale bar (shown in $C$ ): $A, B, 100 \mu \mathrm{m} ; C, 50 \mu \mathrm{m} ; D, 75 \mu \mathrm{m}$.
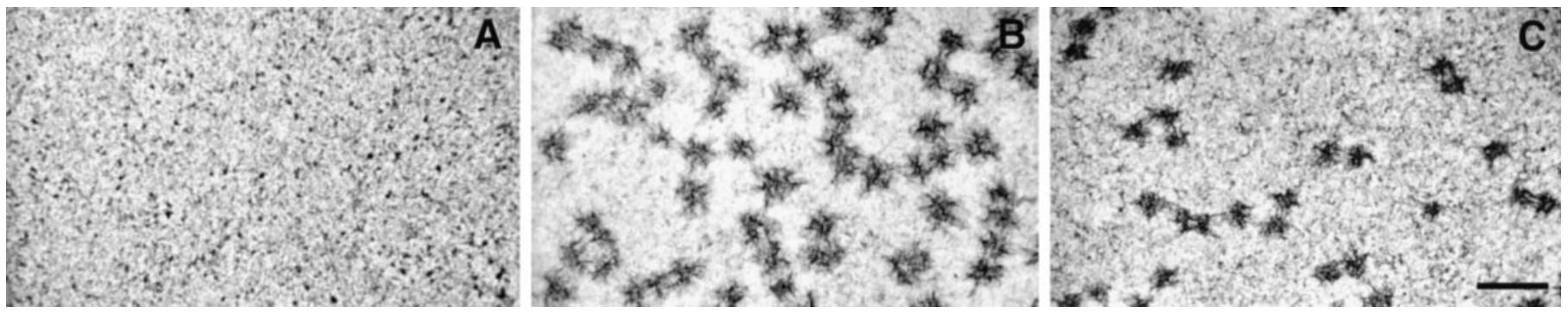

Figure 4. PRV plaque formation on PK-15 cells after infection with urine ( $96 \mathrm{hr})$ or spinal cord (115 hr) samples from nondenervated ACD-inoculated rats with stage 2 cystitis. $A$, Viral titration of urine sample results in no plaque formation at dilutions that would detect $>10^{2} \mathrm{pfu} / \mathrm{ml}$. $B$, Mixing of PRV with the urine sample from the same animal in $A$ results in numerous plaques (darkly stained clusters). The number of plaques detected after mixing was similar to the input pfu. $C$, Culture of the lumbosacral spinal cord resulted in abundant plaque formation. Scale bar (shown in $C$ ): $A, B, 8 \mathrm{~mm} ; C, 6 \mathrm{~mm}$.

ported previously (Nadelhaft et al., 1992; Sugaya et al., 1997). After limb inoculation, as for the ACD, Barrington's nucleus always became infected at least $24 \mathrm{hr}$ after the LC.

\section{Immune response in the CNS}

iNOS immunostaining allowed visualization of entry, progression, and distribution of monocytes in the spinal cord and brain during viral infection (Akaike et al., 1995). iNOS delineated dark and uniformly stained round cellular profiles of $10 \pm 2 \mu \mathrm{m}$ of average diameter. These were determined to be leukocytes because they first appeared in the vicinity of dilated blood vessels (Fig. 5, right panel, 72 hrs), and their distribution was identical to that of ED1 staining or that of monocytes identified on H\&E-stained sections (data not shown). iNOS staining was not found in the CNS of control, noninfected rats, as reported previously (Goff et al., 1998). In the gray matter, iNOS was dense and overlapped PRV immunolabeling, although it appeared with an approximate $24 \mathrm{hr}$ time lag. Because inflammatory cells accumulated equally over both neuronal perikarya and dendrites, iNOS labeling appeared to extend beyond that of PRV (Fig. 5, right panel, 84 hrs and 96 $h r s)$, leading to the presence of iNOS cells in areas where viral 

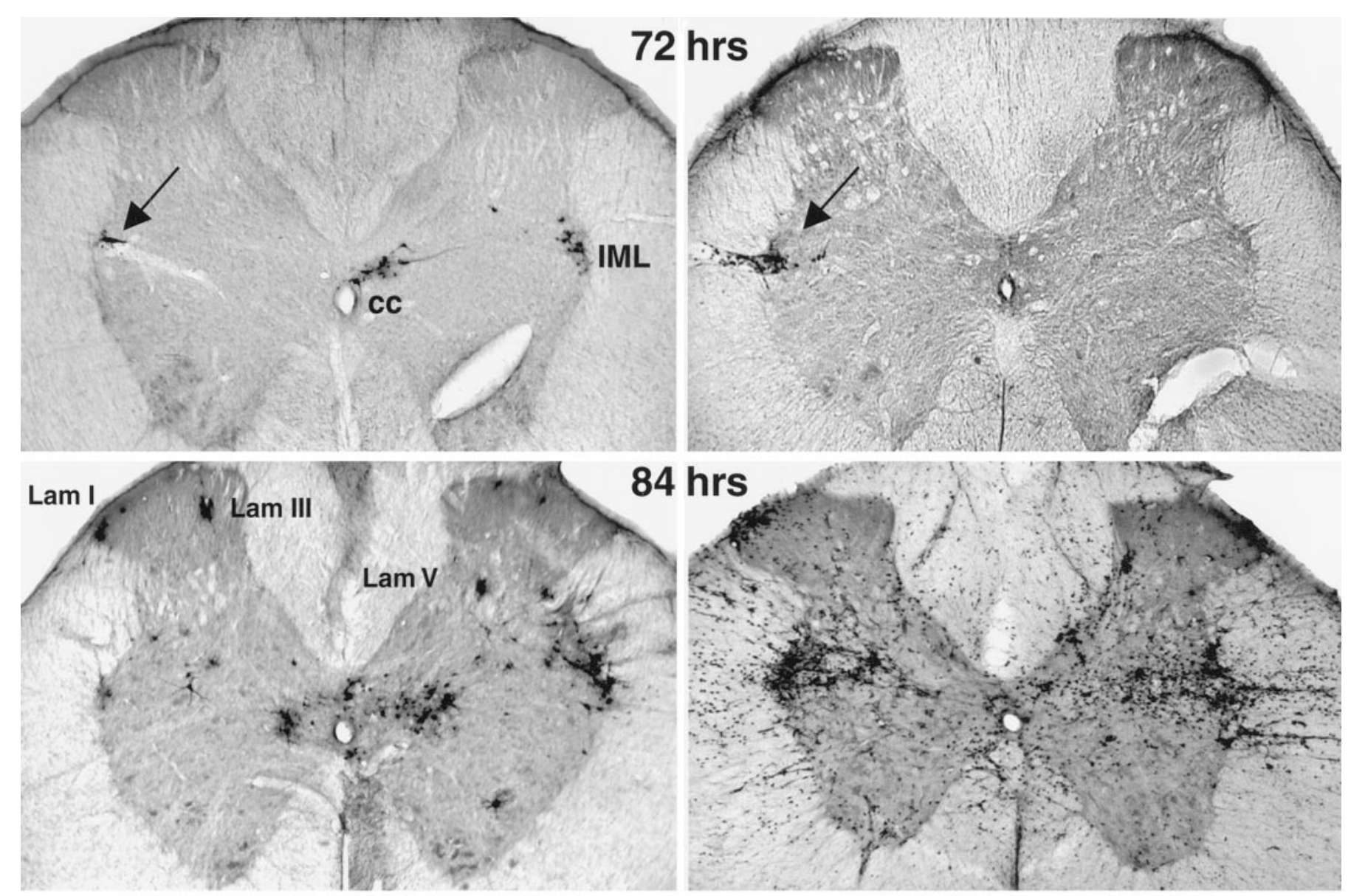

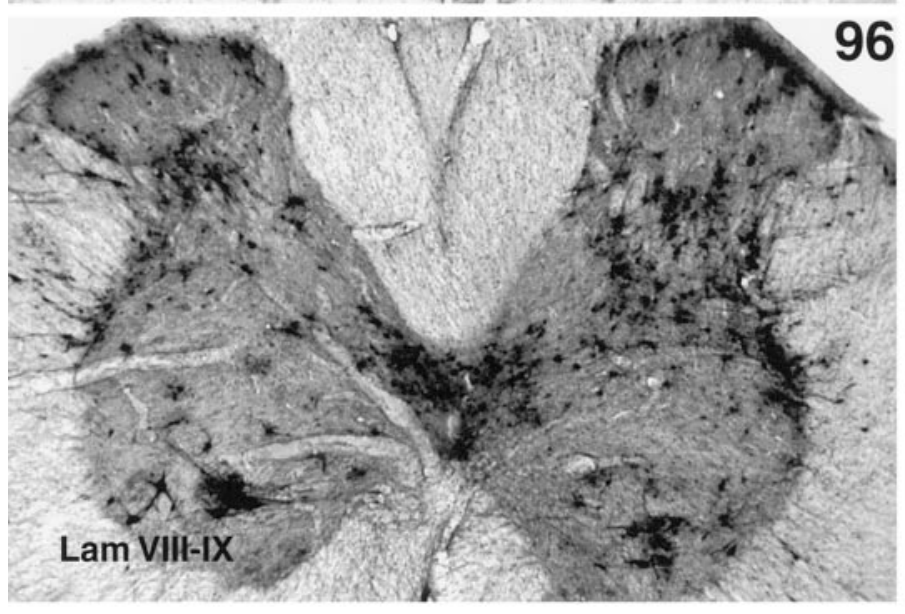

PRV

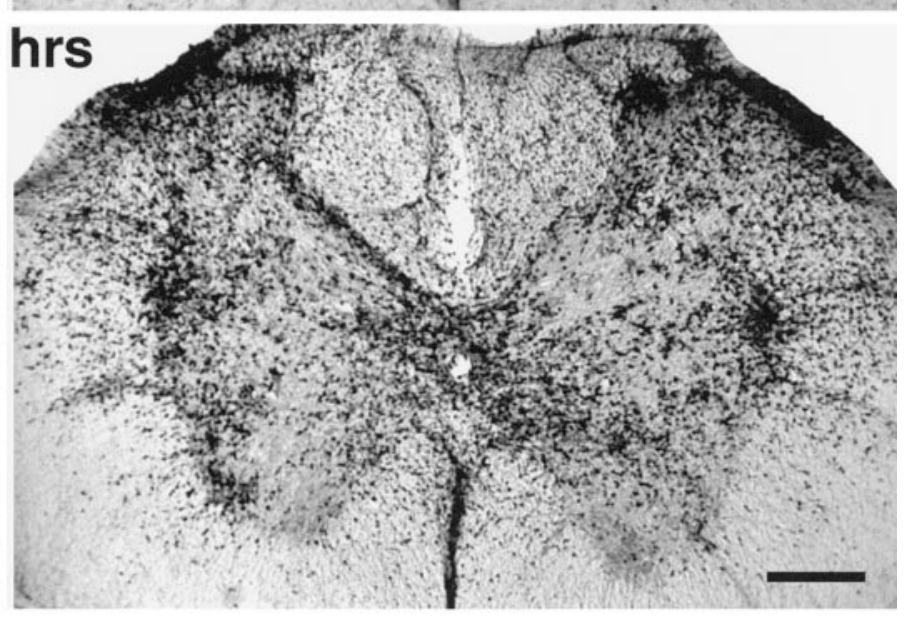

iNOS

Figure 5. Transverse sections of the rostral lumbar spinal cord (L1-L2) of nondenervated rats at three different post-inoculation times. Sections from each rat have been immunostained for either PRV or iNOS. The spread of the virus is slow and well localized, whereas the progression of iNOS is more rapid and extensive, overlapping infected areas in the gray matter as well as invading adjacent areas in the white matter. At $72 \mathrm{hr}$, PRV has spread to both the sympathetic preganglionic neurons $(I M L)$ and central canal area neurons $(c c)$. iNOS-immunolabeled cells only begin to invade the spinal cord in areas where the virus is found. Initially, iNOS-immunoreactive cells are located in and around dilated blood vessels, as seen here on adjacent sections in a radially oriented dilated blood vessel at the level of the left IML (arrows). At $84 \mathrm{hr}$, viral invasion has progressed to both the dorsal and ventral horns (laminae I and III and VIII and IX, respectively). The total number of infected cells, however, remains modest. Conversely, the density of iNOS-immunopositive cells has increased exponentially, although they are still concentrated in the areas where the virus is found. At $96 \mathrm{hr}$, PRV is present throughout the dorsoventral extent of the spinal gray matter, being concentrated in autonomic and nociceptive areas [laminae I and II, reticulated area of the dorsal horn (lateral lamina V), cc, and IML]. iNOS is most abundant in these areas, with significant involvement in the adjacent white matter. Scale bar: $250 \mu \mathrm{m}$. 

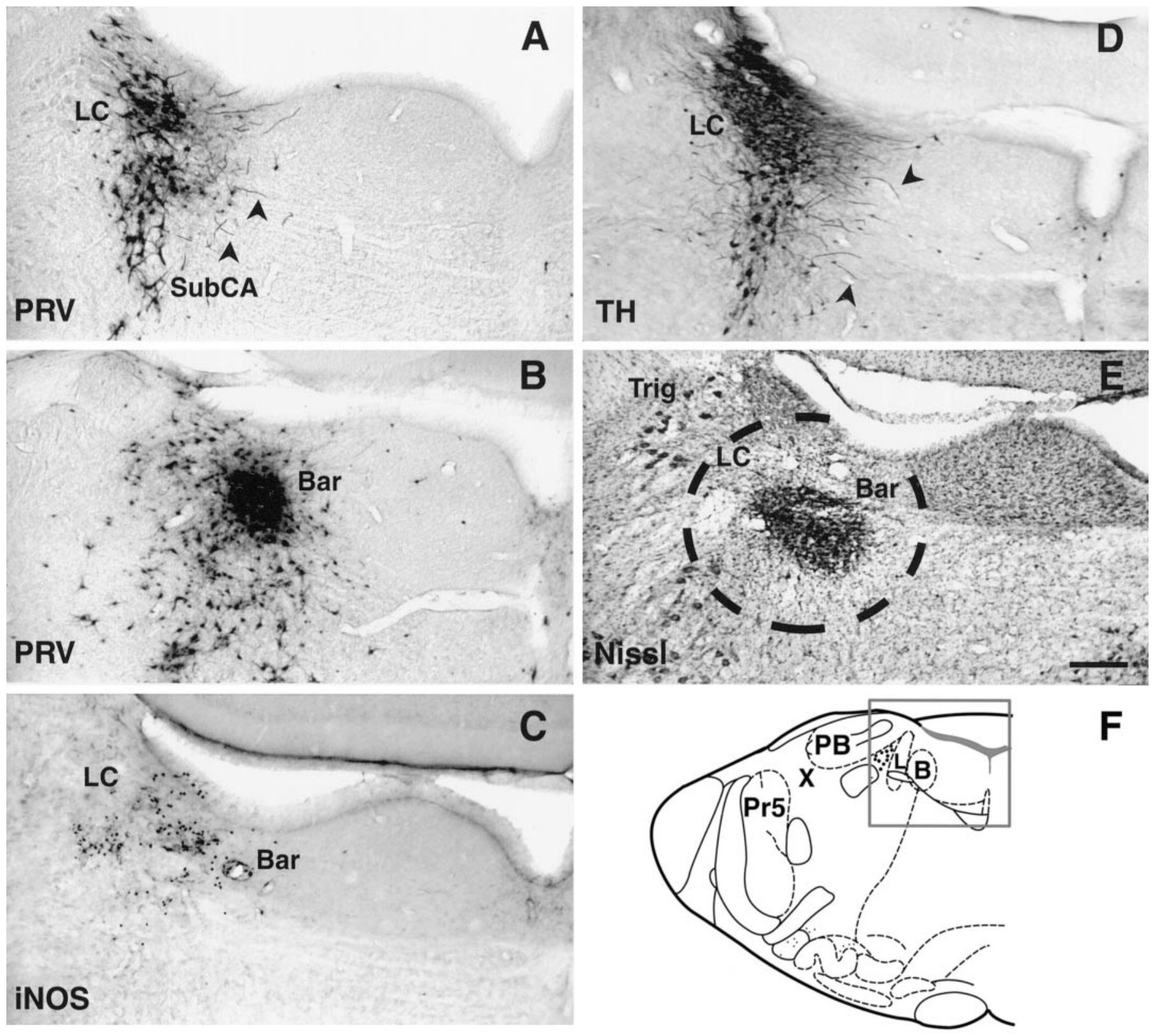

Figure 6. Medial half of the caudal pons on transverse sections of the brainstem. A, PRV immunostaining $96 \mathrm{hr}$ after ACD inoculation in a rat with moderate cystitis (macroscopic stage 2). Labeled neurons are confined to the locus coeruleus $(L C)$ and subcoeruleus $(S u b C A)$. Dendrites are seen extending medially (arrowheads). B, PRV immunostaining $96 \mathrm{hr}$ after inoculation of the bladder wall. The bladder in this rat was normal. Note the dense labeling in Barrington's nucleus (Bar), with sparser labeling that extends radially in the surrounding reticular formation. A few PRV-immunopositive cells are seen in the LC and SubCA. $C$, iNOS immunostaining of an adjacent section from the same animal as in $A$. Immunopositive cells overlap both the $L C$ and $B a r$. Notice the dilated blood vessel in Bar surrounded by labeled cells. These cells were identified as circulating leukocytes on H\&E-stained sections. $D$, TH immunostaining of another section from the animal in $A$ and $C$. Labeling is localized to the same areas as PRV immunostaining. Note again long dendrites extending medially toward Bar (arrowheads). E, Nissl-stained section from a different rat, $130 \mathrm{hr}$ after PRV inoculation in the ACD. Bilateral excitotoxic lesions of the Bar/LC area were made before inoculation. The bladder of this rat showed no inflammation. The lesion is delineated by the interrupted line. Within these limits, we observe dense gliosis and outlines of darkly or lightly stained degenerated neurons. PRV and TH immunostaining were sparse and mostly located at the lateral border of the LC adjacent to the mesencephalic trigeminal nucleus (Trig). F, Schematic representation of a transverse section of the caudal pons. The boxed area corresponds to the areas pictured in $A-E$. The location of the locus coeruleus $(L)$ and Barrington's nucleus $(B)$ has been indicated. The location of control (off-site) excitotoxic lesions is indicated by an $X$, centered in the reticular formation between to the parabrachial complex $(P B)$ and the primary sensory trigeminal nucleus $(\operatorname{Pr} 5)$. These control animals all developed a moderate, but not severe, inflammation of the bladder. Diagram adapted from Figure 57 of the atlas of Paxinos and Watson (1997). Scale bar (shown in $E$ ): $A-E, 200 \mu \mathrm{m}$.

immunoreactivity was not seen. This was especially noticeable for Barrington's nucleus in ACD-inoculated rats (Fig. 6C), where a large core of dendrites extend from the LC (Fig. 6D). Immune cells infiltrated Barrington's nucleus approximately when the first signs of cystitis appeared (Fig. 6C).

\section{Effect of selective peripheral denervation on the appearance of bladder inflammation}

Total denervation of the bladder by removal of both pelvic ganglia, lesion of capsaicin-sensitive primary bladder afferents, or pregangli- 


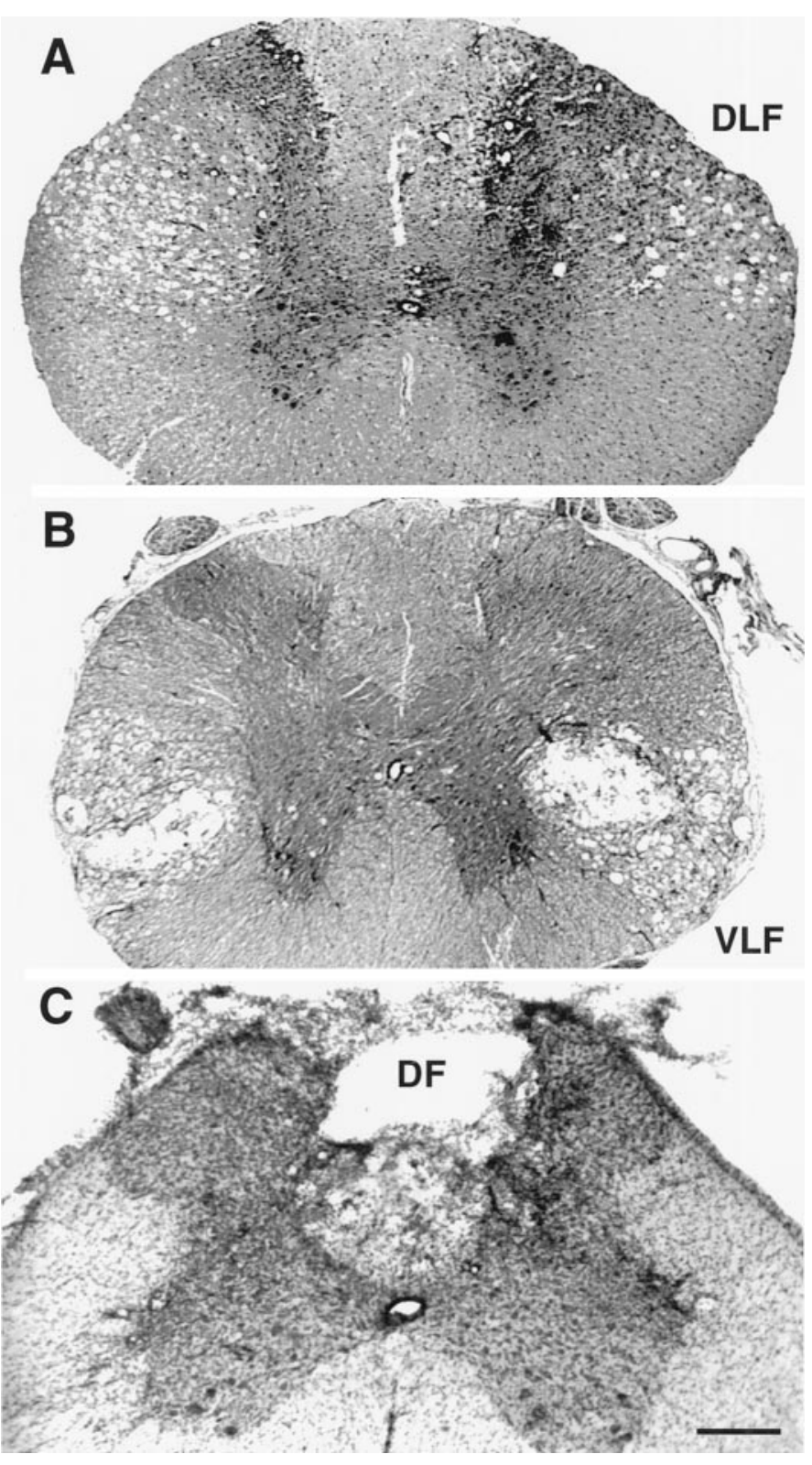

Figure 7. Nissl-stained transverse spinal cord sections in rats having undergone bilateral funiculi lesions before PRV inoculation. $A$, T8 dorsolateral funiculi $(D L F) ; B$, T8 ventrolateral funiculi $(V L F) ; C$, L1 dorsal funiculi $(D F)$ lesions. Rat with DLF and VLF lesions had no inflammation of the bladder despite a long post-inoculation delay (136 hr) allowing extensive viral spread and signs of CNS disease $(+++)$. In sharp contrast, all rats with DF lesions had bladder inflammation indistinguishable from sham controls. Scale bar, $250 \mu \mathrm{m}$.

onic sympathectomy by section of the intermesenteric nerve all consistently prevented bladder inflammation after ACD inoculation (Table 1). Behavioral as well as macroscopical or histological signs of cystitis were absent (Fig. 3B), and plasma extravasation could not be detected (Fig. 2), although all animals manifested overt signs of CNS infection. These signs included scratching of the flanks and grooming of the base of the tail, but without any behavior directed to the abdomen as in rats with cystitis. Immunocytochemistry of the spinal cord revealed viral progression and distribution identical to that of nondenervated rats.

Not all peripheral denervation, however, prevented cystitis. Signs of bladder inflammation developed in all ACD-inoculated rats hav- ing undergone unilateral pelvic ganglionectomy or hypogastric nerve section and in half of those with bilateral hypogastric nerve section (Table 1). In this latter group, it is possible that the sympathetic innervation of the bladder was not entirely removed because of the presence of an accessory branch from the hypogastric ganglion to the bladder (Jänig and McLachlan, 1987). Again, the progression and distribution of PRV immunolabeling in the CNS was essentially the same as in nondenervated rats, as would be expected given that the routes of viral entry from the ACD remained intact.

\section{Effect of selective central denervation on the appearance of bladder inflammation}

Bilateral lesions of the DLF or VLF of the spinal cord served to partially interrupt the central pathways related to the bladder, leaving its peripheral innervation intact (Fig. 7A,B). Although rats inoculated in the ACD manifested signs of spinal (scratching of the flanks, excessive grooming of the base of the tail and the hindpaws) and supraspinal viral invasion (anorexia, perturbed sleep-wake cycle, etc.) (data not shown), none developed cystitis. Surprisingly, immunostaining demonstrated that PRV had spread to the same spinal and brainstem areas as in sham-operated controls or nonoperated rats (compare Fig. 8 with Fig. $1 D$, Fig. 8 PONS with Fig. $6 A$, and Fig. $8 \mathrm{Ll}$ with Fig. 5 PRV, 96 hrs), although a decrease in labeled neurons in the nucleus of the solitary tract were observed after DLF lesions. Because PRV is transported retrogradely in the CNS (Card et al., 1990), this result suggests that brainstem pathways innervating the spinal preganglionic neurons related to the ACD have projections traveling in the VLF in addition to those of the DLF. It should be stressed, however, that the time course of viral spread was not followed after these partial spinal lesions. It is therefore possible that at shorter times post-inoculation, these lesions prevented spread from the spinal cord to many brainstem areas. The long post-inoculation observation period in rats with funiculus sections, used to ensure that no late cystitis eventually developed, could have permitted the virus to indirectly infect these brainstem areas through connections with areas rostral to the lesion, in which passage of PRV had not been interrupted.

Not unexpectedly from the above results, complete spinal transection at T8 prevented the appearance of bladder inflammation, as well as viral labeling rostral to the lesion, whereas the viral labeling caudal to the section was the same as in normal rats. Bilateral lesion of the DF (Fig. 7C), however, did not affect the course of the cystitis, which was indistinguishable from that seen in sham-operated rats as determined anatomically and with the Evans blue dye plasma extravasation method (Fig. 2). Of note, the DF, unlike the DLF or the VLF, has not been reported to contain ascending or descending projections related to bladder function.

Brainstem lesions completely blocked the appearance of cystitis only when they included Bar/LC bilaterally (Fig. 6E), an effect that was independent of the timing of the lesion in relation to the viral inoculation. These lesions of $\sim 600-800 \mu \mathrm{m}$ in diameter never included the entire LC, whereas they covered most but not all of both Barrington's nuclei and were restricted to the area where these two nuclei are adjacent (Fig. 6E,F). TH immunoreactivity within the borders of the lesion was almost absent, and Nissl staining showed replacement of the Barrington's neurons by dense gliosis (Fig. 6E). The residual cells from this nucleus, however, were concluded to be functional because none of the animals presented urinary retention as described previously for complete lesions (Barrington, 1925). In rats with unilateral Bar/LC lesions, a partial reduction in the degree of bladder inflammation was none- 

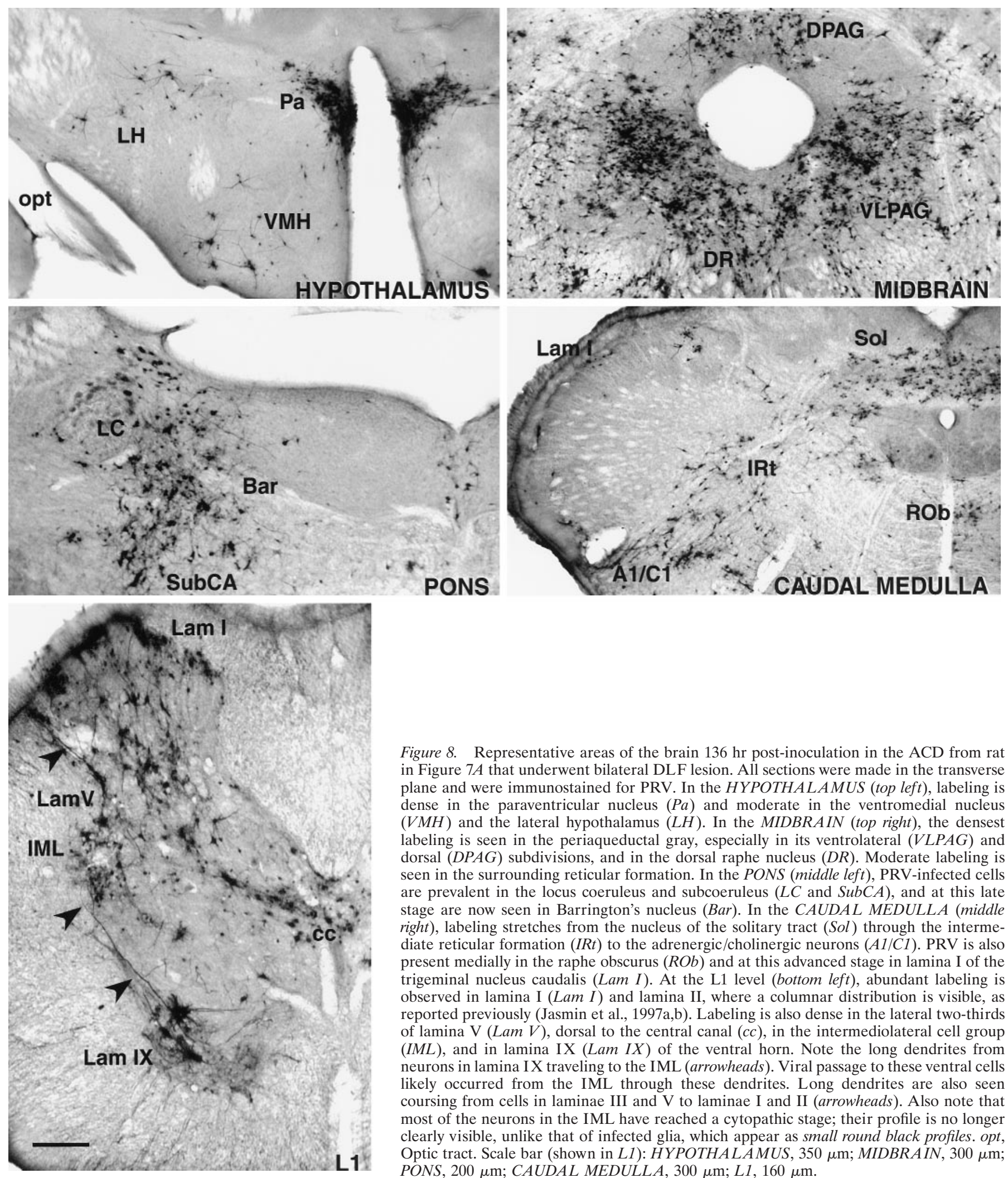

Figure 8. Representative areas of the brain $136 \mathrm{hr}$ post-inoculation in the ACD from rat in Figure $7 A$ that underwent bilateral DLF lesion. All sections were made in the transverse plane and were immunostained for PRV. In the HYPOTHALAMUS (top left), labeling is dense in the paraventricular nucleus $(\mathrm{Pa})$ and moderate in the ventromedial nucleus $(V M H)$ and the lateral hypothalamus $(L H)$. In the MIDBRAIN (top right), the densest labeling is seen in the periaqueductal gray, especially in its ventrolateral (VLPAG) and dorsal $(D P A G)$ subdivisions, and in the dorsal raphe nucleus $(D R)$. Moderate labeling is seen in the surrounding reticular formation. In the PONS (middle left), PRV-infected cells are prevalent in the locus coeruleus and subcoeruleus ( $L C$ and $S u b C A$ ), and at this late stage are now seen in Barrington's nucleus (Bar). In the CAUDAL MEDULLA (middle right), labeling stretches from the nucleus of the solitary tract ( $\mathrm{Sol}$ ) through the intermediate reticular formation (IRt) to the adrenergic/cholinergic neurons $(A 1 / C 1)$. PRV is also present medially in the raphe obscurus $(R O b)$ and at this advanced stage in lamina I of the trigeminal nucleus caudalis (Lam I). At the L1 level (bottom left), abundant labeling is observed in lamina I ( $\operatorname{Lam~I)}$ and lamina II, where a columnar distribution is visible, as reported previously (Jasmin et al., 1997a,b). Labeling is also dense in the lateral two-thirds of lamina $\mathrm{V}(\operatorname{Lam} V)$, dorsal to the central canal $(c c)$, in the intermediolateral cell group $(I M L)$, and in lamina IX (Lam IX) of the ventral horn. Note the long dendrites from neurons in lamina IX traveling to the IML (arrowheads). Viral passage to these ventral cells likely occurred from the IML through these dendrites. Long dendrites are also seen coursing from cells in laminae III and V to laminae I and II (arrowheads). Also note that most of the neurons in the IML have reached a cytopathic stage; their profile is no longer clearly visible, unlike that of infected glia, which appear as small round black profiles. opt, Optic tract. Scale bar (shown in L1): HYPOTHALAMUS, $350 \mu \mathrm{m}$; MIDBRAIN, $300 \mu \mathrm{m}$; PONS, $200 \mu \mathrm{m}$; CAUDAL MEDULLA, $300 \mu \mathrm{m} ; L 1,160 \mu \mathrm{m}$.

theless observed. Although bilateral lesions of the adjacent reticular formation (indicated by $X$ in Fig. $6 F$ ) also reduced the severity of the cystitis, they did not prevent its appearance. None of these lesions significantly altered spinal viral spread. Rare viral-infected cells were seen within the lesion area.

\section{DISCUSSION}

Most of our knowledge of nervous system involvement in inflammation concerns its peripheral components. Neuromediators released by primary afferents as well as sympathetic and parasympa- 
thetic postganglionic fibers will cause and/or enhance plasma extravasation (Heller et al., 1994; Delepine and Aubineau, 1997). Still, little is known about the mechanisms by which the CNS could activate sensory or autonomic neurons to produce inflammation. The present study demonstrates that a CNS disease can produce neurogenic inflammation (cystitis) via activation of central bladder circuits in specific spinal cord and brainstem areas.

To understand how viral infection of the CNS could cause the appearance of cystitis, we followed the spread of PRV in the nervous system. After ACD inoculation, PRV enters the CNS through motor and sympathetic, but not through sensory, neurons (Jasmin et al., 1997b). We and others have found a very reproducible pattern of CNS infection after ACD, bladder, or limb inoculation, with productive infection occurring in neurons only (Card et al., 1990, 1993; Strack and Loewy, 1990; Nadelhaft et al., 1992; Rotto-Percelay et al., 1992; Rinaman et al., 1993; Jasmin et al., 1997b; Sugaya et al., 1997). Viral spread is essentially transsynaptic with the immune response limiting nonspecific spread. This response consists of early activation of glia surrounding infected neurons and later leukocyte invasion (Rinaman et al., 1993; Card and Enquist, 1995). We propose that the development of cystitis is attributable to this immune response activating somatic and autonomic neural circuits.

In rats with cystitis, viral replication and leukocyte infiltration occurred both in spinal regions harboring preganglionic bladder neurons and in regions where primary sensory bladder afferents terminate. In contrast, in nondenervated rats without cystitis, viral invasion in these spinal areas and associated immune responses had not yet occurred, because of either too short an interval post-inoculation or predominance of infection in other spinal areas (i.e., after limb inoculation). Unexpectedly, after bladder inoculation with a similar spinal distribution of PRV and immune cells as in ACD-inoculated animals, cystitis was a rare occurrence. This is likely attributable to PRV directly inactivating spinal preganglionic autonomic neurons responsible for producing cystitis before spreading to the CNS.

PRV-infected neurons undergo an early arrest of normal protein synthesis leading to a "shut down" of many metabolic processes (Berthomme et al., 1993), likely to reduce excitability and neurotransmitter release. By expressing viral proteins, however, these compromised neurons induce an immune response (Mettenleiter, 1996) that could activate neighboring uninfected neurons, setting off events leading to the peripheral inflammation. Cytokines and NO released by immune cells lower the depolarization threshold of neighboring neurons by increasing the availability of, or response to, excitatory neurotransmitters such as glutamate, acetylcholine, or corticotropin releasing hormone (CRH) (Raber et al., 1994, 1995; Ye and Sontheimer, 1996; Raber and Bloom, 1996). Interestingly, in our model a viscerosomatic interaction occurs, possible because of the close proximity in the spinal cord of autonomic circuits to the bladder and tail muscles. Accordingly, ACD inoculation always resulted in a neurogenic cystitis, whereas bladder inoculation led to an inflammation of the tail base. A similar link between visceral and somatic neural circuits was reported after activation of uterine afferents induced cutaneous plasma extravasation at the base of the tail (Wesselmann and Lai, 1997).

To generate peripheral inflammation, neuroactive substances released by immune cells would lead to antidromic potentials in the central branch of dorsal root ganglion neurons, a phenomenon termed dorsal root reflex (Rees et al., 1996). Although there is no previous disease model in which the CNS is the primary initiator of peripheral inflammation, there is ample evidence of spinally medi- ated neurogenic inflammation induced by a stimulus to a distant body area (Denko and Petricevic, 1978; Levine et al., 1985a,b; Kolston et al., 1991; Bileviciute et al., 1993; Wesselmann and Lai, 1997). Accordingly, modulation of spinal non-NMDA, GABA-A, $\mathrm{A}_{1}$ adenosine, or nicotinic receptors reduces peripheral inflammation (Miao et al., 1992; Rees et al., 1994, 1995, 1996; Bong et al., 1996). Abnormal activity of spinal interneurons would result in activation of the central branch of primary sensory afferents, leading to increased peripheral release of proinflammatory neuropeptides (Sluka et al., 1994; Rees et al., 1996). Therefore, removal of capsaicin-sensitive fibers, many of which contain these neuropeptides, blocks this inflammation.

The absence of cystitis after resiniferatoxin treatment indicates that $\mathrm{C}$-fiber primary afferents were necessary for the appearance of the bladder inflammation. In the bladder, capsaicin-sensitive fibers constitute a large proportion $(60 \%)$ of both sensory and most of the substance-P-containing fibers (Holzer et al., 1982; Hu-Tsai et al., 1992). Our finding therefore agrees with previous observations of a contribution of peptidergic unmyelinated primary afferents to neurogenic inflammation (Ahluwalia et al., 1994; Baluk, 1997; McDonald et al., 1996). Because resiniferatoxin treatment does not desensitize sympathetic fibers (Cervero and McRitchie, 1982), these were ruled out as being solely responsible for the cystitis. Whether sympathetic innervation is necessary to produce inflammation along with sensory innervation remains unresolved (Heller et al., 1994; Sluka et al., 1994; Rees et al., 1995). Even in light of the preventative effects of hypogastric or intermesenteric nerve section on the development of cystitis, the present study cannot provide conclusive evidence, because sectioning these nerves removes sympathetic as well as some sensory bladder afferents (Neuhuber, 1982; Baron and Jänig, 1991). Paravertebral sympathectomy could not serve to isolate the role of sensory fibers because this procedure also denervates the ACD from sympathetics, thus removing the major route of viral entry in the spinal cord (Jasmin et al., 1997b), resulting, not unexpectedly, in the absence of cystitis (L. Jasmin unpublished observations). Our results nonetheless demonstrate that postganglionic sympathetics are not sufficient to induce the bladder inflammation (i.e., they are preserved after intermesenteric nerve section); if sympathetic activity plays a causal role, it would be through activation of preganglionic IML neurons. The consistency of PRV immunoreactivity and leukocyte migration in the sacral and lumbar IML and superficial dorsal horn in rats with cystitis suggests that primary sensory neurons as well as sympathetic and parasympathetic preganglionic neurons were activated.

The absence of bladder inflammation after bilateral DLF or VLF lesions additionally implicates supraspinal circuits. The evidence is twofold. First, these funiculi contain brainstemdescending projections, and second, lesions of Bar/LC prevented cystitis. Particular attention was paid to Barrington's nucleus after we observed that it consistently became invaded by iNOSimmunopositive cells in animals developing cystitis. The absence of PRV in Barrington's nucleus at the time cystitis appeared suggested that it was functionally intact. Barrington's nucleus (Barrington, 1921), or pontine micturition center, is involved in bladder function through direct projections to sacral preganglionic neurons via the DLF (Loewy et al., 1979; Lumb and Morrison, 1987; Sugaya et al., 1987; Mallory et al., 1991). This effect is mediated in part through the excitatory neurotransmitter $\mathrm{CRH}$ (Valentino et al., 1995). The LC in turn would project to the spinal cord through both the VLF and DLF, as suggested by the identical labeling of this nucleus after lesion of either tract. 
Because NO facilitates neuronal release of CRH (Brunetti, 1994; McCann et al., 1997; Mancuso et al., 1998) and bilateral Bar/LC lesions prevented cystitis, we propose that these two nuclei contribute to the generation of bladder inflammation through descending spinal projections. The circuits involved could include many of Barrington's nucleus $\mathrm{CRH}$ projection sites, in addition to the LC, some of which affect peripheral inflammation, including the dorsal motor nucleus of the vagus and the hypothalamus (Brown, 1986; Coderre et al., 1990; Caroleo et al., 1993; Valentino et al., 1995; Baerwald and Panayi, 1997; Sternberg, 1997).

Among our most consistent findings was that no viscera other than the bladder were inflamed, suggesting a greater susceptibility of the bladder to neurogenic inflammation. The severity of the inflammatory response in the bladder, however, could be aggravated by the systemic immune response to the CNS viral disease. The release of neuropeptides and other proinflammatory mediators by nerve terminals in the bladder could induce the initial plasma extravasation (Heller et al., 1994). These neuropeptides also induce increased expression of endothelial adhesion molecules (Matis et al., 1990; Hosoi et al., 1993). This in turn would attract circulating leukocytes, increased in number because of the systemic immune response to the virus, producing a positive feedback mechanism that aggravates the initial plasma extravasation. Thus, the severity of the cystitis could be related to this combination of initial local increased neural activity followed by massive migration of circulating immune cells, leading to a high amount of inflammatory mediators.

The significance of this study is that it demonstrates the role of the CNS in the initiation of peripheral inflammation, as suggested previously (Levine et al., 1985a,b; Sluka et al., 1995). The mechanisms are likely multiple, involving not only peripheral release of neurotransmitters but also dysfunction of either the immune or endocrine systems, or both (Sternberg, 1997). Finally, this study uncovers the unique potential of neurotropic viruses as tools to bring about neuroimmune interactions in vivo.

\section{REFERENCES}

Ahluwalia A, Maggi CA, Santicioli P, Lecci A, Giuliani S (1994) Characterization of the capsaicin-sensitive component of cyclophosphamide-induced inflammation in the rat urinary bladder. $\mathrm{Br} \mathbf{J}$ Pharmacol 111:1017-1022.

Akaike T, Weihe E, Schaefer M, Fu ZF, Zheng YM, Vogel W, Schmidt H, Koprowski H, Dietzschold B (1995) Effect of neurotropic virus infection on neuronal and inducible nitric oxide synthase activity in rat brain. J Neurovirol 1:118-125.

Baerwald CG, Panayi GS (1997) Neurohumoral mechanisms in rheumatoid arthritis. Scand J Rheumatol 26:1-3.

Baluk P (1997) Neurogenic inflammation in skin and airways. J Invest Dermatol Symp Proc 2:76-81.

Baranowski R, Lynn B, Pini A (1986) The effects of locally applied capsaicin on conduction in cutaneous nerves in four mammalian species. Br J Pharmacol 89:267-276.

Baron R, Jänig W (1991) Afferent and sympathetic neurons projecting into lumbar visceral nerves of the male rat. J Comp Neurol 314:429-436.

Baron R, Jänig W, Kollmann W (1988) Sympathetic and afferent somata projecting in hindlimb nerves and the anatomical organization of the lumbar sympathetic nervous system of the rat. J Comp Neurol 275:460-468.

Barrington FJF (1921) The relation of the hind-brain to micturition. Brain 44:23-53.

Barrington FJF (1925) The effect of lesions of the hind- and midbrain on micturition in the cat. Q J Exp Physiol Cogn Med Sci 15:81-102.

Berthomme H, Jacquemont B, Epstein A (1993) The pseudorabies virus host-shutoff homolog gene: nucleotide sequence and comparison with alphaherpesvirus protein counterparts. Virology 193:1028-32.

Bileviciute I, Lundeberg T, Ekblom A, Theodorsson E (1993) Bilateral changes of substance $\mathrm{P}-$, neurokinin $\mathrm{A}-$, calcitonin gene-related peptide- and neuropeptide Y-like immunoreactivity in rat knee joint synovial fluid during acute monoarthritis. Neurosci Lett 153:37-40.

Bon K, Lantéri-Minet M, De Pommery J, Michiels JF, Menétrey D (1996) Cyclophosphamide cystitis as a model of visceral pain in rats. A survey of hindbrain structures involved in visceroception and nociception using the expression of c-Fos and Krox-24 proteins. Exp Brain Res 108:404-416.

Bong GW, Rosengren S, Firestein GS (1996) Spinal cord adenosine receptor stimulation in rats inhibits peripheral neutrophil accumulation. The role of $N$-methyl-D-aspartate receptors. J Clin Invest 98:2779-2785.

Bouma A, Zwart RJ, De Bruin MGM, De Jong MCM, Kimman TG, Bianchi ATJ (1997) Immunohistological characterization of the local cellular response directed against pseudorabies virus in pigs. Vet Microbiol 58:145-154.

Brown M (1986) Corticotropin releasing factor: central nervous system sites of action. Brain Res 399:10-14.

Brunetti L (1994) Nitric oxide: a gas as a modulator of neuroendocrine secretions [Erratum (1994) 144:199]. Clin Ter 144:147-153.

Callsen-Cencic P, Mense S (1997) Expression of neuropeptides and nitric oxide synthase in neurones innervating the inflamed rat urinary bladder. J Auton Nerv Syst 65:33-44.

Card JP, Enquist L (1995) Neurovirulence of pseudorabies virus. Crit Rev Neurobiol 9:137-162.

Card JP, Rinaman L, Schwaber JS, Miselis RR, Whealy ME, Robbins AK, Enquist LW (1990) Neurotropic properties of pseudorabies virus: uptake and transneuronal passage in the rat central nervous system. J Neurosci 10:1974-1994.

Card JP, Rinaman L, Lynn RB, Lee BH, Meade RP, Miselis RR, Enquist LW (1993) Pseudorabies virus infection of the rat central nervous system: ultrastructural characterization of viral replication, transport, and pathogenesis. J Neurosci 13:2515-2539.

Caroleo MC, Pulvirenti L, Arbitrio M, Lopilato R, Nistico G (1993) Evidence that $\mathrm{CRH}$ microinfused into the locus coeruleus decreases cell-mediated immune response in rats. Funct Neurol 8:271-277.

Carr J, Wilhelm DL (1964) The evaluation of increased vascular permeability in the skin of guinea pigs. Aust J Exp Biol Med Sci 42:511-522.

Cervero F, McRitchie HA (1982) Neonatal capsaicin does not affect unmyelinated efferent fibers of the autonomic nervous system: functional evidence. Brain Res 239:283-288.

Coderre TJ, Basbaum AI, Dallman MF, Helms C, Levine JD (1990) Epinephrine exacerbates arthritis by an action at presynaptic B2adrenoceptors. Neuroscience 34:521-523.

Cox PJ (1979) Cyclophosphamide cystitis: identification of acrolein as the causative agent. Biochem Pharmacol 28:2045-2049.

Craft RM, Cohen SM, Porreca F (1995) Long-lasting desensitization of bladder afferents following intravesical resiniferatoxin and capsaicin in the rat. Pain 61:317-323.

Delepine L, Aubineau P (1997) Plasma protein extravasation induced in the rat dura mater by stimulation of the parasympathetic sphenopalatine ganglion. Exp Neurol 147:389-400.

Denko CW, Petricevic M (1978) Sympathetic or reflex footpad swelling due to crystal-induced inflammation in the opposite foot. Inflammation 3:81-86.

Goff JR, Burkey AR, Goff DJ, Jasmin L (1998) Reorganization of the spinal dorsal horn in models of chronic pain: correlation with behaviour. Neuroscience 82:559-574.

Grossman ML, Basbaum AI, Fields HL (1982) Afferent and efferent connections of the rat tail flick reflex (a model used to analyze pain control mechanisms). J Comp Neurol 206:9-16.

Gustavson DP (1986) Pseudorabies. In: Diseases of swine (Leman AD, Straw B, Glock RD, Mengeling WL, Penny RHC, Scholl E, eds), pp 274-289. Ames, IA: Iowa State UP.

Heller PH, Green PG, Tanner KD, Miao FJ-P, Levine JD (1994) Peripheral neural contributions to inflammation. In: Pharmacological approaches to the treatment of chronic pain (Fields HL, Liebeskind JC, eds), pp 31-42. Seattle: IASP.

Holzer P, Bucsics A, Lembeck F (1982) Distribution of capsaicinsensitive nerve fibres containing immunoreactive substance $\mathrm{P}$ in cutaneous and visceral tissues of the rat. Neurosci Lett 31:253-257.

Hosoi J, Murphy GF, Egan CL, Lerner EA, Grabbe S, Asahina A, Granstein RD (1993) Regulation of Langerhans cell function by nerves containing calcitonin gene-related peptide. Nature 363:159-163.

Hu-Tsai M, Winter J, Woolf CJ (1992) Regional differences in the distribution of capsaicin-sensitive target-identified adult rat dorsal root ganglion neurons. Neurosci Lett 143:251-254.

Iadecola C, Arneric SP, Baker HD, Tuker LW, Reis DJ (1987) Role of 
local neurons in cerebrocortical vasodilatation elicited from the cerebellum. Am J Physiol 252:1082-1091.

Jancsó G, Lawson SN (1990) Transganglionic degeneration of capsaicinsensitive C-fiber primary afferent terminals. Neuroscience 39:501-511.

Jänig W, McLachlan EM (1987) Organization of lumbar spinal outflow to distal colon and pelvic organs. Physiol Rev 67:1332-1404.

Jasmin L, Burkey AR, Card JP, Basbaum AI (1997a) Transneuronal labeling of a nociceptive pathway, the spino(trigemino-)parabrachioamygdaloid, in the rat. J Neurosci 17:3751-3765.

Jasmin L, Carstens E, Basbaum AI (1997b) Interneurons presynaptic to rat tail-flick motoneurons as mapped by transneuronal transport of pseudorabies virus: few have long ascending collaterals. Neuroscience 76:859-876.

Kolston J, Lisney SJ, Mulholland MN, Passant CD (1991) Transneuronal effects triggered by saphenous nerve injury on one side of a rat are restricted to neurones of the contralateral, homologous nerve. Neurosci Lett 130:187-189.

Lantéri-Minet M, Bon K, De Pommery J, Michiels JF, Menétrey D (1995) Cyclophosphamide cystitis as a model of visceral pain in rats: model elaboration and spinal structures involved as revealed by the expression of c-Fos and Krox-24 proteins. Exp Brain Res 105:220-232.

Lecci A, Giuliani S, Santicioli P, Maggi CA (1994) Involvement of spinal tachykinin NK1 and NK2 receptors in detrusor hyperreflexia during chemical cystitis in anaesthetized rats. Eur J Pharmacol 259:129-135.

Levine JD, Collier DH, Basbaum AI, Moskowitz MA, Helms CA (1985a) Hypothesis: the nervous system may contribute to the pathophysiology of rheumatoid arthritis. J Rheumatol 12:406-411.

Levine JD, Dardick SJ, Basbaum AI, Scipio E (1985b) Reflex neurogenic inflammation. I. Contribution of the peripheral nervous system to spatially remote inflammatory responses that follow injury. J Neurosci 5:1380-1386.

Liao G, Maillard M, Kiraly M (1991) Ion channels involved in the presynaptic hyperexcitability induced by herpes virus suis in rat superior cervical ganglion. Neuroscience 41:797-807.

Loewy AD, Saper CB, Baker RP (1979) Descending projections from the pontine micturition center. Brain Res 172:533-538.

Lumb BM, Morrison JF (1987) An excitatory influence of dorsolateral pontine structures on urinary bladder motility in the rat. Brain Res 435:363-366.

Maggi CA, Lippe IT, Giuliani S, Abelli L, Somma V, Geppetti P, Jancsó G, Santicioli P, Meli A (1989) Topical versus systemic capsaicin desensitization: specific and unspecific effects as indicated by modification or reflex micturition in rats. Neuroscience 31:745-756.

Mallory BS, Roppolo JR, de Groat WC (1991) Pharmacological modulation of the pontine micturition center. Brain Res 546:310-320.

Mancuso C, Tringali G, Grossman A, Preziosi P, Navarra P (1998) The generation of nitric oxide and carbon monoxide produces opposite effects on the release of immunoreactive interleukin- $1 \beta$ from the rat hypothalamus in vitro: evidence for the involvement of different signaling pathways. Endocrinology 139:1031-1037.

Martinez-Piñeiro L, Dahiya R, Nunes LL, Tanagho EA, Schmidt RA (1993) Pelvic plexus denervation in rats causes morphologic and functional changes of the prostate. J Urol 150:215-218.

Matis WL, Lavker RM, Murphy GF (1990) Substance P induces the expression of an endothelial-leukocyte adhesion molecule by microvascular endothelium. J Invest Dermatol 94:492-495.

McCann SM, Kimura M, Karanth S, Yu WH, Rettori V (1997) Nitric oxide controls the hypothalamic-pituitary response to cytokines. Neuroimmunomodulation 4:98-106.

McDonald DM, Bowden JJ, Baluk P, Bunnett NW (1996) Neurogenic inflammation. A model for studying efferent actions of sensory nerves. Adv Exp Med Biol 410:453-462.

McMahon SB, Abel CA (1987) A model for the study of visceral pain states: chronic inflammation of the chronic decerebrate rat urinary bladder by irritant chemicals. Pain 28:109-127.

Mettenleiter TC (1996) Immunobiology of pseudorabies (Aujeszky's disease). Vet Immunol Immunopathol 54:221-229.

Meunier M, Destrade C (1988) Electrolytic but not ibotenic acid lesions of the posterior cingulate cortex produce transitory facilitation of learning in mice. Behav Brain Res 27:161-173.

Miao FJ, Helms C, Benowitz NL, Basbaum AI, Heller PH, Levine JD (1992) Chronically administered nicotine attenuates bradykinininduced plasma extravasation and aggravates arthritis-induced joint injury in the rat. Neuroscience 51:649-655.

Milligan CE, Cunningham TJ, Levitt P (1991a) Differential immunochemical markers reveal the normal distribution of brain macrophages and microglia in the developing rat brain. J Comp Neurol 314:125-135.
Milligan CE, Levitt P, Cunningham TJ (1991b) Brain macrophages and microglia respond differently to lesions of the developing and adult visual system. J Comp Neurol 314:136-146.

Nadelhaft I, Booth AM (1984) The location and morphology of preganglionic neurons and the distribution of visceral afferents from the rat pelvic nerve: a horseradish peroxidase study. J Comp Neurol 226:238-245.

Nadelhaft I, Vera PL (1995) Central nervous system neurons infected by pseudorabies virus injected into the rat urinary bladder following unilateral transection of the pelvic nerve. J Comp Neurol 359:443-456.

Nadelhaft I, Vera PL, Card JP, Miselis RR (1992) Central nervous system neurons labelled following the injection of pseudorabies virus into the rat urinary bladder. Neurosci Lett 143:271-274.

Neuhuber W (1982) The central projections of visceral primary afferent neurons of the inferior mesenteric plexus and hypogastric nerve and the location of the related sensory and preganglionic sympathetic cell bodies in the rat. Anat Embryol 164:413-425.

Petsche U, Fleischer E, Lembeck F, Handwerker HO (1983) The effect of capsaicin application to a peripheral nerve impulse conduction in functionally identified afferent nerve fibers. Brain Res 265:233-240.

Raber J, Bloom FE (1996) Arginine vasopressin release by acetylcholine or norepinephrine: region-specific and cytokine-specific regulation. Neuroscience 71:747-759.

Raber J, Pich EM, Koob GF, Bloom FE (1994) IL-1 beta potentiates the acetylcholine-induced release of vasopressin from the hypothalamus in vitro, but not from the amygdala. Neuroendocrinology 59:208-217.

Raber J, Koob GF, Bloom FE (1995) Interleukin-2 (IL-2) induces corticotropin-releasing factor (CRF) release from the amygdala and involves a nitric oxide-mediated signaling: comparison with the hypothalamic response. J Pharmacol Exp Ther 272:815-824.

Rees H, Sluka KA, Westlund KN, Willis WD (1994) Do dorsal root reflexes augment peripheral inflammation? NeuroReport 5:821-824.

Rees H, Sluka KA, Westlund KN, Willis WD (1995) The role of glutamate and GABA receptors in the generation of dorsal root reflexes by acute arthritis in the anaesthetized rat. J Physiol (Lond) 484:437-446.

Rees H, Sluka KA, Lu Y, Westlund KN, Willis WD (1996) Dorsal root reflexes in articular afferents occur bilaterally in a chronic model of arthritis in rats. J Neurophysiol 76:4190-4193.

Rinaman L, Card JP, Enquist LW (1993) Spatiotemporal responses of astrocytes, ramified microglia, and brain macrophages to central neuronal infection with pseudorabies virus. J Neurosci 13:685-702.

Rotto-Percelay DM, Wheeler JG, Osorio FA, Platt KB, Loewy AD (1992) Transneuronal labeling of spinal interneurons and sympathetic preganglionic neurons after pseudorabies virus injections in the rat medial gastrocnemius muscle. Brain Res 574:291-306.

Sluka KA, Lawand NB, Westlund KN (1994) Joint inflammation is reduced by dorsal rhizotomy and not by sympathectomy or spinal cord transection. Ann Rheum Dis 53:309-314.

Sluka KA, Willis WD, Westlund KN (1995) The role of dorsal root reflexes in neurogenic inflammation. Pain Forum 4:141-149.

Sternberg EM (1997) Neural-immune interactions in health and disease. J Clin Invest 100:2641-2647.

Strack AM, Loewy AD (1990) Pseudorabies virus: a highly specific transneuronal cell body marker in the sympathetic nervous system. J Neurosci 10:2139-2147.

Such G, Jancsó G (1986) Axonal effects of capsaicin: an electrophysiological study. Acta Physiol Hung 67:53-63.

Sugaya K, Matsuyama K, Takakusaki K, Mori S (1987) Electrical and chemical stimulations of the pontine micturition center. Neurosci Lett 80:197-201.

Sugaya K, Roppolo JR, Yoshimura N, Card JP, De Groat WC (1997) The central neural pathways involved in micturition in the neonatal rat as revealed by the injection of pseudorabies virus into the urinary bladder. Neurosci Lett 223:197-200.

Valentino RJ, Pavcovich LA, Hirata H (1995) Evidence for corticotropinreleasing hormone projections from Barrington's nucleus to the periaqueductal gray and dorsal motor nucleus of the vague in the rat. J Comp Neurol 363:402-422.

Vizzard MA, Erdman SL, De Groat WC (1996) Increased expression of neuronal nitric oxide synthase in bladder afferent pathways following chronic bladder irritation. J Comp Neurol 370:191-202.

Wesselmann U, Lai J (1997) Mechanisms of referred visceral pain: uterine inflammation in the adult virgin rat results in neurogenic plasma extravasation in the skin. Pain 73:309-317.

Ye ZC, Sontheimer H (1996) Cytokine modulation of glial glutamate uptake: a possible involvement of nitric oxide. NeuroReport 7:2181-2185. 